Article

\title{
Spatial and Temporal Differences in the Relationships between Residents' Income and Consumption in China: A Dynamic Analysis Using Functional Data Analysis
}

\author{
Deqing Wang ${ }^{1}$, Yan $\mathrm{Xu}^{2}$, Lingyun $\mathrm{He}^{1, *(1)}$ and Rongyan Liu ${ }^{1}$ \\ 1 School of Management, China University of Mining and Technology, Daxue Road 1, Xuzhou 221116, China; \\ dekinywang@cumt.edu.cn (D.W.); ts17070011a3tm@cumt.edu.cn (R.L.) \\ 2 Corporate Business Department, Bank of Jiangsu Xuzhou Branch, Pengcheng Road 81, Xuzhou 221003, \\ China; xuyangrace@hotmail.com \\ * Correspondence: Lingyun_he@cumt.edu.cn; Tel.: +86-138-5248-3411
}

Received: 1 November 2018; Accepted: 5 December 2018; Published: 10 December 2018

\begin{abstract}
Income inequality and consumption gaps between urban and rural residents are prominent problems in the economic transition phase of China. Stimulating consumption, expanding domestic demand, and shifting development modes are inevitable choices for maintaining China's economy with healthy, stable, and endogenous growth, and the key premise is to clarify the coordination relationship between residents' income and consumption. In view of that, this study incorporates the spatial factors of three economic zones and time factors of China's economic transition into an analytical framework. By transforming discrete data into continuous functions, we compared the regional differences and temporal characteristics of the relationship between residents' income and consumption based on the two perspectives of static absolute level and dynamic growing speed. The result shows that: (1) There are significant differences in the absolute levels of original income and consumption among residents in the eastern, middle, and western regions of China, whereas the growing velocity and acceleration of income and consumption do not have significant regional differences. (2) There is a highly positive canonical correlation both in the absolute growth amount and dynamic growth potential of residents' income and consumption, whereas their nonlinear co-variation has obvious temporal characteristics, and the degree of canonical correlation has significant regional differences. Based on these conclusions, China's government need not consider regional factors too much when formulating and implementing policies to narrow residents' income gap and stimulating consumption in order to expand domestic demand, but should discriminate the specific coevolving period of income and consumption and take into account the difference in average consumption rate of different social strata.
\end{abstract}

Keywords: income inequality; consumption gaps; functional data analysis; spatial and temporal difference

\section{Introduction}

The balance between consumption and income is central for the government to formulate macroeconomic policies. Since Keynes [1] put forward the absolute income hypothesis, the short-term fluctuation and long-term equilibrium relationship between income and consumption have been a permanent hot issue in economics [2,3]. China is currently in the critical period of economic transition, especially affected by the current Sino-U.S. trade war, and a traditional extensive development model that relies heavily on investment and export that cannot ensure the sustained, stable, and rapid growth of China's economy. Therefore, expanding domestic demand, especially stimulating consumer demand, is an important measure for the government to address this crisis and stabilize the economy. 
It must be noted that both the size of the population and the growth potential of income imply that China's consumption level has large room for upward improvement [4,5]. However, the actual situation shows that China is still facing multiple plights, such as the declining rate of total consumption, too large a gap between regional and urban-rural residents' consumption, and the proportion of increasing government consumption expenditure while residents' consumption expenditures decreases [5-8]. During the "13th Five-Year Plan," the critical period for China to moderate a prosperous society in all respects, stimulating domestic demand, especially the consumption demand of residents, is the inevitable choice to realize the endogenous growth of China's economy, and the key premise is to find out and eliminate the chronic obstacles that restrict residents' consumption. Among numerous factors affecting the consumption demand of residents, income, especially its huge gaps, are key factors that cannot be ignored; they not only restrict the whole consumption level of residents but also directly relate to the rationalization of the consumption structure of residents [9-11]. In fact, as a developing country with a typical two-pole economic structure, China has long-standing problems, such as unbalanced economic development between urban and rural areas and large income gaps among residents in different regions, which has led to significant regional and temporal differences in the stimulating effect of income promotion on the consumption of growth [12-16]. However, with the coordinated development of industry structure and regional economies under the "One Belt One Road Initiative," income constraints and consumption patterns of rural residents and underdeveloped areas are changing fundamentally. As a result, residents in rural and underdeveloped areas may demand the increasingly popular service consumptions, such as transportation, education, and healthcare, more and faster than residents do in developed and urban regions [17,18]. Although the Keynesian absolute income hypothesis holds that there are differences in marginal propensity to consume among different income groups, and the degree of urban and rural inequality is related positively to the consumption gap of residents [1,19], the standard life cycle-permanent income hypothesis holds the opposite view that consumers' marginal propensity is not related to income distribution, which means the law of declined marginal consumption is uncertain, and there may even be a negative effect $[4,20,21]$. Therefore, to residents, the idea that income inequality aggravates or narrows their consumption gap remains controversial in theory, and there needs to be further investigations by empirical research as to whether there are significant differences in the consumption tendency of different income groups.

As China's economy steps into the "new normal" phase, the urgent problem that needs to be solved first is changing the development mode of the economy to achieve endogenous growth. The important initiative to achieve the above goals is enhancing residents' consumption levels and optimizing their consumption structure, and its key premise is clarifying the intrinsic relationship correctly between residents' income and consumption. However, due to the constraints of China's industry structure, separation of urban and rural investments in facility construction, aggravation of aging population and changing concept of pension system, and the coevolving process of residents' income and consumption exhibit obvious nonlinear temporal characteristics [14,22,23] with significant regional differences $[5,12,16,24]$. Targeting the above problems and taking the income and consumption of urban and rural residents in the eastern, middle, and western regions of China as study subjects, this paper introduces non-parametric and nonlinear methods of functional data analysis (FDA) to study the co-varying patterns and evolution processes of residents' income and consumption from interactive static and dynamic perspectives. The objective of this study is to explore regional differences, evolution characteristic, and reasons of income inequality and consumption gaps of residents in China. The results can provide empirical references for Chinese governments when formulating and implementing polices to enhance consumption level, optimize consumption structure, and stimulate domestic demand. 


\section{Relationship between Residents' Income and Consumption}

The changing gap of consumption and income is the core index to measure synergetic development of urban and rural areas and common prosperity of residents. As China's economy has typical two pole structure, the existing obvious temporal characteristics and regional disparity in residents' income and consumption is not only related to the natural conditions and the initial development foundation of different regions, but also related to the different regional and industrial policies implemented since the founding of the People's Republic of China. Since regional differences of economic development and dynamic change of economic system are two important perspectives to study the relationship between income and consumption, targeting the purpose of this paper, this part summarizes the research status of the relationship between Chinese residents' income and consumption with regard to the above two aspects.

\subsection{Status of Residents' Income and Consumption in China}

The two prominent characteristics of China's economic development are the extreme imbalances among the eastern, middle, and western economic zones and the huge disparity of industrial structures in the three economic zones. By comparing the division of the three economic zones in Figure 1 and their corresponding data in Figure 2, it can be easily seen that, although the eastern territory area only accounts for 13.5 percent of China's total land area, the proportion of its population is as high as 41 percent, and its gross domestic product (GDP) has always accounted for more than 60 percent of the country's gross domestic product. Meanwhile, the eastern zone is rich in high-tech industries and superior education resources. In sharp contrast, the western zone, which accounts for more than 50 percent of China's total land area, has maintained its regional gross domestic product at a level of approximately 15 percent of the national GDP, accompanied by the relative scarcity of basic education, health care, and other basic public services. Although the disparity in GDP per capita among the economic zones began to decline in 2005, in which a series of reforms in the education funding guarantee mechanism and improving distribution structure of national income were implemented [24], the gap between the eastern zone and the other two zones are still huge, with a stable trend. The reason lies in an influx of labor force, including talents and ordinary workers, who were attracted by high-quality educational resources and public services in the eastern zone. Whereas, limited by the slowly increasing per capita capital, the marginal product of labor declined, resulting in a declining GDP per capita. Given the western zone as benchmark, the comparison of per capita income and consumption among zones in Figure 2 shows that the absolute level of the eastern zone is far more than that of the other two zones: 1.5 times as much as that of the western zone and 3 times higher than that of the middle zone. The above statistical analysis indicated that the regional imbalance of economic development and the gaps between residents' income and consumption have exceeded the reasonable scope of coordinated development [25], and the large lingering gaps in Chinese residents' income and consumption has restricted the expansion of domestic demand and the transformation of the economic development mode [26]. Therefore, under the background of China's economy stepping into a "new normal" phase, promoting residents' overall consumption level and optimizing the consumption structure of residents provide vast opportunities, which not only is one of the directions for changing the extensive modes of economy development and realizing an endogenous growth of China's economy, but is also an important strategy for ensuring social equity and maintaining social stability. 


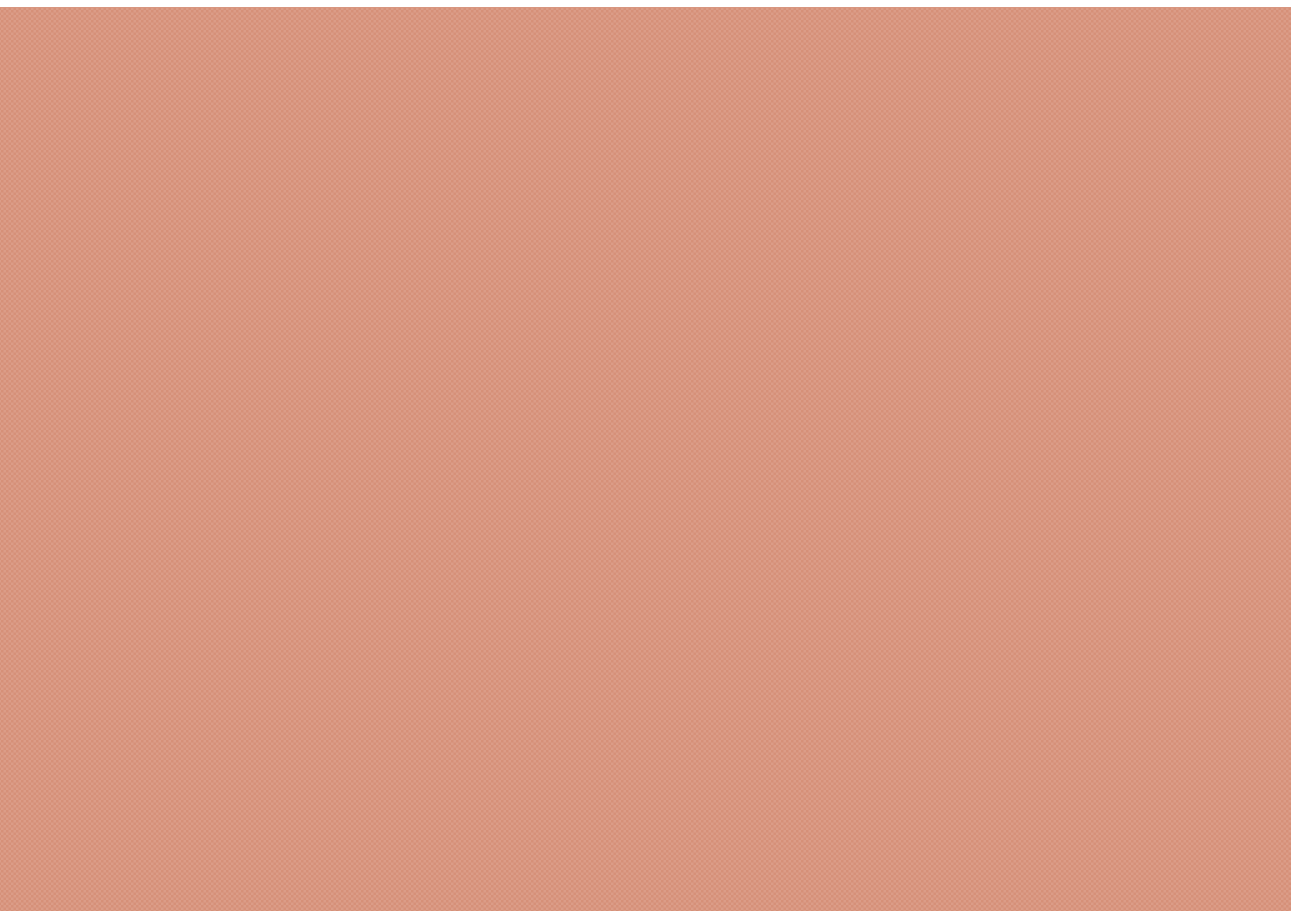

Figure 1. Division of the three economic zones in China.

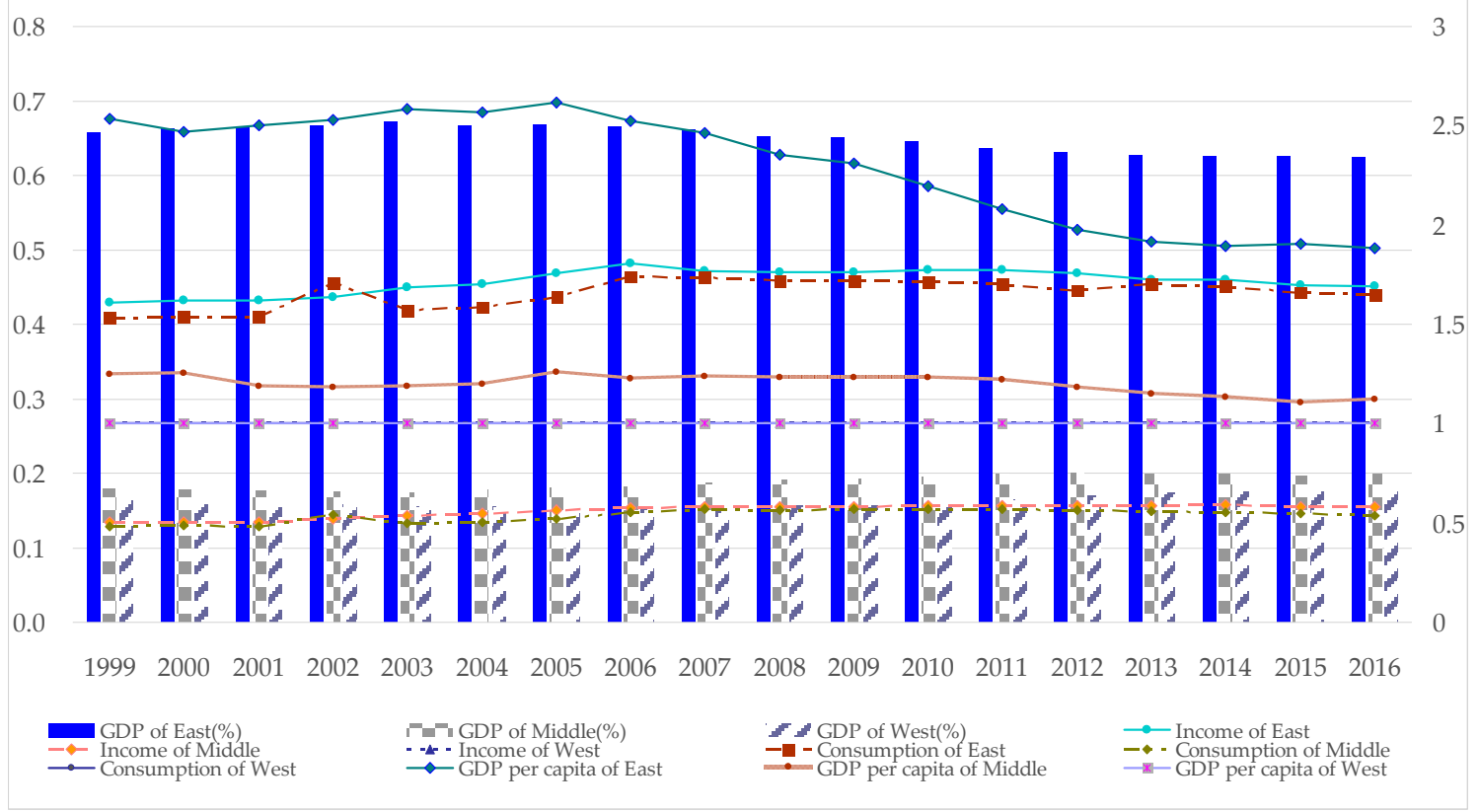

Figure 2. Comparison of regional real GDP, GDP per capita, residents' real income, and consumption between the three economic zones of China during 1999-2016.

\subsection{Literature Review of Residents' Income and Consumption in China}

As one of the most salient features of China's economic performance in the past decades, the internal relationship between urban-rural income inequality and residents' consumption gap has always been an important research topic for domestic and foreign scholars, but there is no consensus regarding theoretical cognitions and empirical conclusions. One view is that, as a typical two-pole economic structure, China's fiscal expenditures on basic public services, such as compulsory education, basic medical care, healthcare, and social security, have obvious regional and urban-rural disparities, and there are significant differences in the level, structure, and marginal propensity of 
residents' consumption $[13,27,28]$. In addition, constrained by different historical stages and differential regional and industrial policies, social inequality characterized by regional and urban-rural income disparities, obviously restrained the improvement of residents' consumption levels in underdeveloped regions or rural regions [29]. As a result, the regional inequality between urban and rural residents' income further deteriorates the gap in residents' consumption [30]. Another perspective is that, with the increase of the per capita income and change in the consumption concept of urban and rural residents, basic services, such as education, medical care, and health are indispensable to the quality of residents' lives [31], which provides immense social demand and an even greater marginal propensity of consumption for residents in underdeveloped or rural regions. The result is that income disparities contribute negative effects to the consumption gap [25,32]. A comparison of study perspectives and content shows that the existing literature either analyzed the relationship of residents' income and consumption within a framework of a single province in isolation, which did not reveal the spatial heterogeneity of income inequality and residents' consumption gaps, or conducted statistical analysis and econometric modeling based on the division of three zones, which focused on the static description of the income and consumption of urban and rural residents. There is not much literature that investigates the law of their potential energy transferring from dynamic perspectives. In light of research methodologies, traditional econometric analysis upon discrete data sampled regularly has difficulty in accurately portraying the continuous dynamic changing process of the relationship between residents' income and consumption, and fixed parameter models failed to depict the nonlinear characteristics of residents' marginal propensity of consumption and elasticity of consumption expenditures during China's economic transition.

Upon reviewing the related literature, it can be found that although numerous scholars have thoroughly studied the relationship with its spatial characteristics of Chinese residents' income and consumption based on the level of economic development, there are still two aspects that require further study: (1) Under a dual economic structure, the imbalance of regional economic development will inevitably lead to regional disparities in residents' income. Given the same increase in income, are there significant differences in the growth of consumption of different regions? How can the robustness of significant differences from static and multiple dynamic perspectives be tested? (2) A consensus has formed stating that there exists is a nonlinear relationship between urban and rural residents' income and consumption in China. Influenced by historical and regional policies, industrial structure adjustment and demographic transitions, the long-term balance between income and consumption is reflected in continuous short-term fluctuations. Thus, mining the continuous dynamic evolution process of residents' income and consumption from their static differences requires the innovation of an analytical framework and research methods. In light of the above problems. and based on the spatial perspective of the division of China's three economic zones and the temporal perspective of the special period of China's economy transition, this study includes the discrete data of the income and consumption of Chinese urban and rural residents from 1999 to 2016 in the framework of continuous, dynamic, and differentiable functions. The objective of this study is to explore the temporal and spatial variations between residents' income and consumption in China.

\section{Framework and Methodology}

The forming process of residents' unbalanced income and consumption gaps among the three economic zones of China was not a short period, and maintaining the long-term equilibrium relationship between income and consumption required residents to adjust consumption behavior and structure dynamically in light of their income situation. It is noted that parametric linear modeling methods have difficulty in depicting the nonlinear process of transforming from short-term fluctuations to long-term equilibrium. In contrast to those existing studies, this study first reconstructs the intrinsic functions of residents' income and consumption using the non-parametric nonlinear modeling methods of functional data analysis (FDA). Second, this study employs functional variance analysis to test the static and dynamic significant differences of income and consumption among the three economic 
zones, and further graphically analyzes the potential energy laws of transferring from short-term fluctuations to long-term equilibrium. Finally, functional canonical correlation analysis is carried out to detect the temporal characteristics and spatial differences of the correlation degree between residents' income and consumption.

\subsection{Reconstructing Functions from Discrete Observations}

The main methods of reconstructing intrinsic continuous functions from discrete data includes interpolation and smoothing, their core difference lies in the presence or absence of disturbance factors. Considering the universality of practical problems, the sample observation $y_{i j}$ is always a noisy realization of intrinsic function $f_{i}\left(t_{j}\right)$, that is $y_{i j}=f_{i}\left(t_{j}\right)+\varepsilon_{i j}$, where $\varepsilon_{i j}$ is random noise commonly assumed to be independent and identically distributed as $N\left(0, \sigma^{2}\right)$; Thus this study mainly discusses the smoothing functional method with roughness penalties to error disturbances. Assuming $\boldsymbol{\Phi}(t)=\left\{\phi_{1}(t), \cdots, \phi_{L}(t)\right\}$ to be the optimal basis function in Hilbert space, the sum of squared fitting residuals for the roughness penalty $\left(P E N S S E_{\kappa}\right)$ is given as follows:

$$
\operatorname{PENSSE}_{\kappa}=\sum_{i=1}^{n}\left\{\sum_{j=1}^{T_{i}}\left[y_{i j}-f_{i}\left(t_{j}\right)\right]^{2}+\kappa \int_{T}\left[f_{i} \prime \prime(t)\right]^{2} d t\right\}
$$

The intrinsic continuous function $f_{i}(t)$ in Equation (1) is a linear approximation of the basis function to meet the criterion of minimizing the PENSSE $E_{\kappa}$, i.e., $f_{i}(t)=\sum_{l=1}^{L} \beta_{i l} \phi_{l}(t)$, where $\beta_{i l}$ denotes the coefficients of the basis function expansion. The smoothing parameter $\kappa$ specifies the proportion between the goodness of model fitting and the smoothing amount of the function curve. Large values of $\kappa$ will increase the amount of smoothing. The best value for the smoothing parameter $\kappa$ is determined by the minimum generalized cross-validation $G C V(\kappa)$. The criterion is given as follows:

$$
G C V(\kappa)=\left(\frac{n}{n-d f(\kappa)}\right)\left(\frac{P E N S S E_{\kappa}}{n-d f(\kappa)}\right)
$$

where the degree of freedom $d f(\kappa)=\operatorname{trace}\left\{\boldsymbol{\Phi}(\boldsymbol{\Phi} / \mathbf{\Phi}+\kappa \mathbf{R})^{-1} \mathbf{\Phi} /\right\}$ and the roughness penalty matrix $\mathbf{R}$ is expressed as $\mathbf{R}=\int D^{2} \phi(s) \cdot D^{2} \phi \prime(s) d s$. Based on the above symbols, solving Equation (1) for $\boldsymbol{\beta}$ will give us $\hat{\boldsymbol{\beta}}=(\boldsymbol{\Phi} / \boldsymbol{\Phi}+\kappa \mathbf{R})^{-1} \boldsymbol{\Phi} / \mathbf{y}$. A complete theoretical review of the penalty smoothing method can be found in Kokoszka et al. (2017) [33], and the steps of the algorithm are detailed in Ramsey et al. (2009) [34]. Using the methodology of reconstructing continuous functions from discrete data in Equation (1), we can infer that FDA does not restrict all samples to be sampled at regular intervals on the observing interval $\mathrm{T}$. The relaxed structure of data collection and hypothesis of distribution enable FDA to depict practical problems more comprehensively and flexibly. Particularly, once the intrinsic functions are reconstructed from the discrete noisy data, we can not only display the continuously changing trajectory of income and consumption statically from the holistic perspective, but also can analyze their dynamic relationships interactively from multiple derivative functions.

\subsection{Significance Test of Difference via Functional Analysis of Variance}

The functional analysis of variance (F-ANOVA) is used to test whether two or more sets of functional data are identical, independent, and come from the same population. The verification was done by comparing the functional means. Let $g$ represent the number of groups or zones, with $f_{i j}\left(i=1, \cdots, g ; j=1, \cdots, n_{i}\right)$ as the $j$ th-functional data for $i$ groups, and $n_{i}$ is the number of 
curves in group $i$. As a first step in F-ANOVA, the classical F statistic in the form of functional data is considered, which is written as:

$$
F_{n}=\frac{\sum_{i=1}^{g} n_{i}\left\|\overline{f_{i .}}-\overline{f_{. .}}\right\|^{2} /(g-1)}{\sum_{i, j}\left\|f_{i j}-\overline{f_{i .}}\right\|^{2} /(n-g)}
$$

where $\|\cdot\|$ denotes the usual $L^{2}$ norm as $\|f\|=\left(\int f^{2}(t) d t\right)^{1 / 2}$. The expressions used in Equation (3) are described by $f_{i j}=\left(f_{i j}\left(t_{1}\right), \cdots, f_{i j}\left(t_{T}\right)\right) \prime, \overline{f_{i .}}=\left(\overline{f_{i .}}\left(t_{1}\right), \cdots, \overline{f_{i .}}\left(t_{T}\right)\right) \prime$, and $\overline{f_{. .}}=\left(\overline{f_{. .}}\left(t_{1}\right), \cdots, \overline{f_{. .}}\left(t_{T}\right)\right) \prime$, which can be computed as $\overline{f_{i .}}(t)=\sum_{j}^{n_{i}} f_{i j}(t) / n_{i}, n=\sum_{i=1}^{g} n_{i}$, and $\overline{f . .}(t)=\sum_{i=1}^{g} n_{i} \overline{f_{i .}}(t) / n . \overline{f_{\text {.. }}}$ is the global functional mean and $\overline{f_{i}}$ is the functional mean in the $i$ th groups, respectively, at time $t$. Given the above symbols, the equivalent statistic of Equation (3) can be rewritten as:

$$
V_{n}=\sum_{i<j}^{g} n_{i}\left\|\overline{f_{i .}}-\overline{f_{j .}}\right\|^{2}
$$

Given the null hypothesis of having the same functional means for each $i$ group, that is, $H_{0}: \overline{f_{1 . .}}=\cdots=\overline{f_{g .}}$, the critical values $P_{H_{0}}\left\{F>F_{n, \alpha}\right\}=\alpha$ and $P_{H_{0}}\left\{V>V_{n, \alpha}\right\}=\alpha$ are calculated at the specified significance level $\alpha$. $H_{0}$ should be rejected if the variability between groups, which are measured by the difference in the sample means $F_{n}$ and $V_{n}$, which is large enough to be expressed as $F_{n}>F_{n, \alpha}$ and $V_{n}>V_{n, \alpha}$. This procedure uses a point-wise critical value obtained using permutation test as reference lines [35,36].

\subsection{Functional Canonical Correlation Analysis}

The main purpose of functional canonical correlation analysis (FCCA) is to analyze the relationship and its changes between two random functions. For the two sets of smooth functions in FCCA, the aim is to estimate a pair of weight functions successively in such a way that the same pair of canonical functions is maximally correlated with each other while uncorrelated with different pairs. Assume $f(t)$ and $g(t)$ are the quadratic integrable functions of Hilbert space $L_{2}(\mathrm{~T})$, and $\Gamma_{12}(s, t)=\operatorname{Cov}[f(s) g(t)]$ is their covariance function. Let $\langle f(t), g(t)\rangle=\int_{T} f(t) g(t) \mathrm{d} t$; then, the first canonical correlation coefficient $\rho_{1}(u, v)$, and its corresponding weight functions $u_{1}(t)$ and $v_{1}(t)$, are expressed as follows:

$$
\rho_{1}(u, v)=\sup _{u, v \in L_{2}(\mathrm{~T})} \iint_{T} u(s) \Gamma_{12}(s, t) v(t) \mathrm{d} s \mathrm{~d} t=\operatorname{Cov}\left(<u_{1}(s), f(s)>,<v_{1}(t), g(t)>\right)
$$

where $u(s)$ and $v(t)$ are subject to the constraints:

$$
\operatorname{Var}(<u(s), f(s)>)=\operatorname{Var}(<v(t), g(t)>)=1
$$

Further, the $k$ th $(\geq 2)$ canonical correlation coefficient $\rho_{k}(u, v)$ and its corresponding weight functions $u_{k}(t)$ and $v_{k}(t)$ are defined as:

$$
\rho_{k}(u, v)=\sup _{u, v \in L_{2}(\mathrm{~T})} \iint_{T} u(s) \Gamma_{12}(s, t) v(t) \mathrm{d} s \mathrm{~d} t=\operatorname{Cov}\left(<u_{k}(s), f(s)>,<v_{k}(t), g(t)>\right)
$$

where $u_{k}$ and $v_{k}$ are subject to Equation (6), and, for $i=1, \cdots, k-1$, the $k$ th pair of canonical variables is uncorrelated with the $(k-1)$ leading pairs, which can be expressed as:

$$
\operatorname{Cov}\left(<u_{k}(s), f(s)>,<u_{i}(t), f(t)>\right)=\operatorname{Cov}\left(<v_{k}(s), g(s)>,<v_{i}(t), g(t)>\right)=0
$$

Let $U_{k}=<u_{k}(s), f(s)>$ and $V_{k}=<v_{k}(t), g(t)>$ be the $k$ th canonical correlation scores on their associated weight functions $u_{k}(t)$ and $v_{k}(t)$, respectively; we shall call $\left(\rho_{k}, u_{k}(t), v_{k}(t), U_{k}, V_{k}\right)$ the $k$ th 
functional canonical components. The complete theoretical review can be found in Leurgans et al. (1993) [37] and Shin et al. (2015) [38], and the steps of the algorithm are detailed in He et al. (2004) [39].

\subsection{Dynamic Analysis upon Principal Differential Equation}

By providing direct access to the relationship between the function itself and its derivatives at the same time, FDA is very useful for studying the continuous dynamics of a system. Let $f_{i}(t)$ be the residents' income or consumption function such that the goal of principal differential analysis (PDA) is to identify a linear operator of the form:

$$
L f_{i}(t)=\beta_{0}(t) f_{i}(t)+\beta_{1}(t) f_{i}^{\prime}(t)+\cdots+\beta_{m-1}(t) f_{i}^{(m-1)}(t)+f^{(m)}(t)
$$

that satisfies the homogeneous linear differential equation $L f_{i}=0$ for each observation $f_{i}$. PDA aims to estimate the operator $L$, defined by the weight function vector $\beta=\left[\beta_{0}(t), \beta_{1}(t), \cdots, \beta_{m-1}(t)\right]^{T}$, by minimizing the sum of squared differential residuals:

$$
\operatorname{SSE}_{P D A}(L)=\sum_{i=1}^{N} \int\left[L f_{i}(t)\right]^{2} d t
$$

The driving idea behind the minimization problem given by Equation (10) is to search for a differential operator that is able to describe a large part of the variability shown by the functional data set $\left\{f_{i}(t)\right\}_{i=1, \cdots, N}$. Once the operator has been identified, the dynamic information about how a system evolves can be captured using a differential equation model, expressed as:

$$
f^{(m)}(t)=-\beta_{0}(t) f_{i}(t)-\beta_{1}(t) f_{i}^{\prime}(t)-\cdots-\beta_{m-1}(t) f_{i}^{(m-1)}(t)
$$

The second-order linear differential equation is generally adopted to study the varying relationship between velocity and acceleration. A complete review of the functional PDA method can be found in Ramsey et al. [40-42].

\section{Empirical Analysis of Spatial and Temporal Difference between Income and Consumption}

\subsection{Data Sources and Reconstruction of Functions}

Based on the division of the three major economic zones (east, middle, and west) of China, this study conducts an empirical analysis on the longitudinal data of residents' income and consumption in 31 provinces of China from 1999 to 2016. The yearly data are from the "Statistical Yearbook of China (2000-2017)" [43], which could be downloaded from the following website: http:/ /www.stats.gov.cn/tisj/ndsj/. In order to eliminate the inflationary impact, assuming 1999 as the base period, we adopted a GDP deflator index to convert nominal GDP to real GDP, and adopted consumer price index to convert nominal income to real income. As the logarithmic transformation does not change the relationship between original variables and can eliminate heteroscedasticity, the subsequent empirical data are all carried out with a logarithmic transformation. In order to remove observational errors, we performed smoothing methods with a roughness penalty to reconstruct the intrinsic functions of income and consumption. Figure 3 displays the $G C V$ against logarithms of different $\kappa$ values to choose the optimal smoothing parameter (left for income and right for consumption). 
a

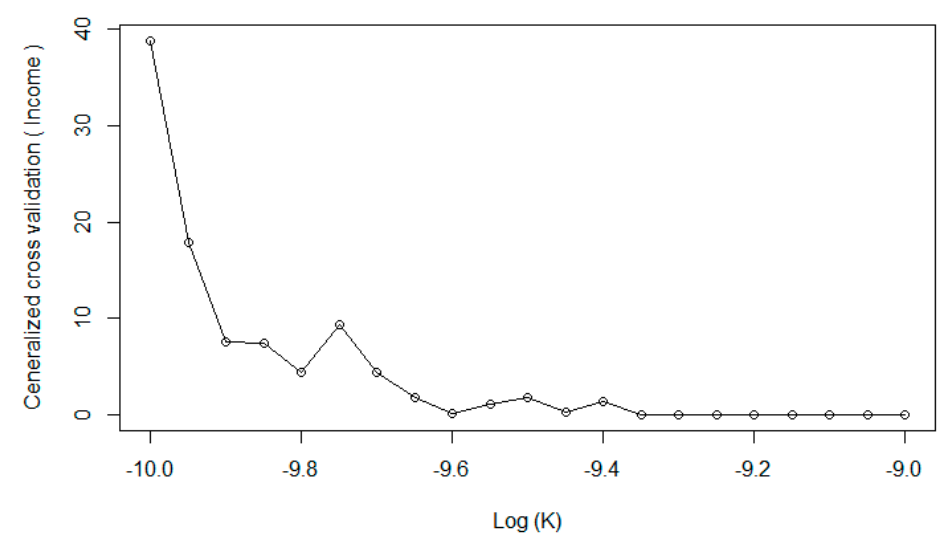

b

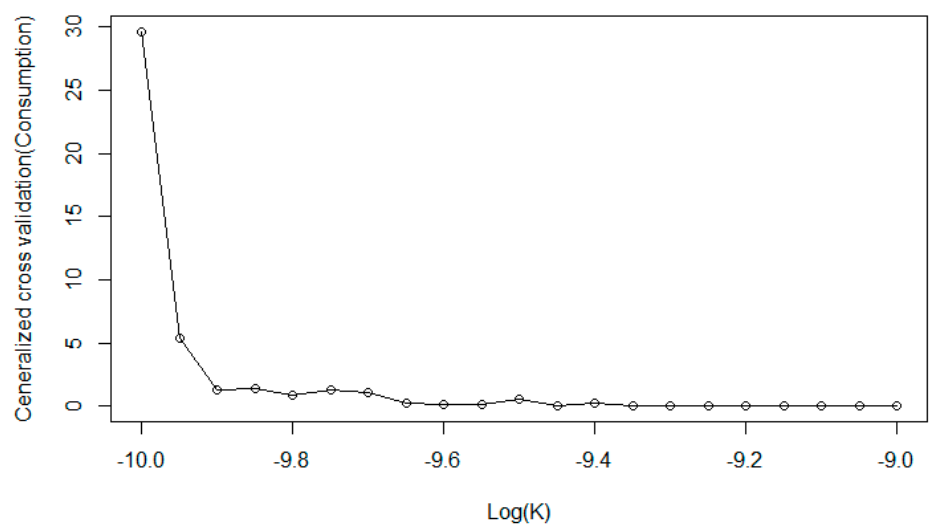

Figure 3. The GCV criterion for choosing the smoothing parameter $\kappa$. (a) Income; (b) Consumption.

As shown in Figure 3, both the two fluctuation trajectories of $G C V(\kappa)$ for income and consumption begin to become horizontal when $\log _{10}^{\kappa}=-9.4$; that is, once the smoothing parameter $\kappa$ is larger than $10^{-9.4}$, both the minimum values of $G C V(\kappa)$ remain stable. In order to keep the comparability of function reconstructing, this study chooses $\kappa=10^{-9}$ as the optimal penalty smoothing parameter to reconstruct functions. The consumption functions of 31 provinces in China and their corresponding first-order and second-order derivative functions are presented in Figure 4, and Figure 5 displays the income function with their first-order and second-order derivatives. The black lines in Figure 4 denote resident's consumption in every province, with (a) for original functions, (b) for velocity, (c) for acceleration, and the red lines denote the overall mean of all provinces. The analogous information for residents' income are presented in Figure 5.
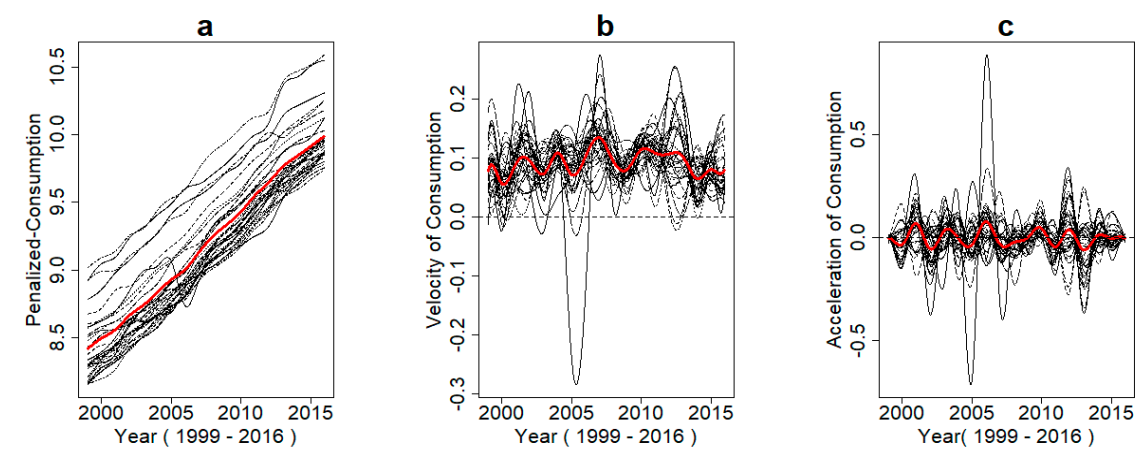

Figure 4. Consumption functions with first-order and second-order derivatives. 

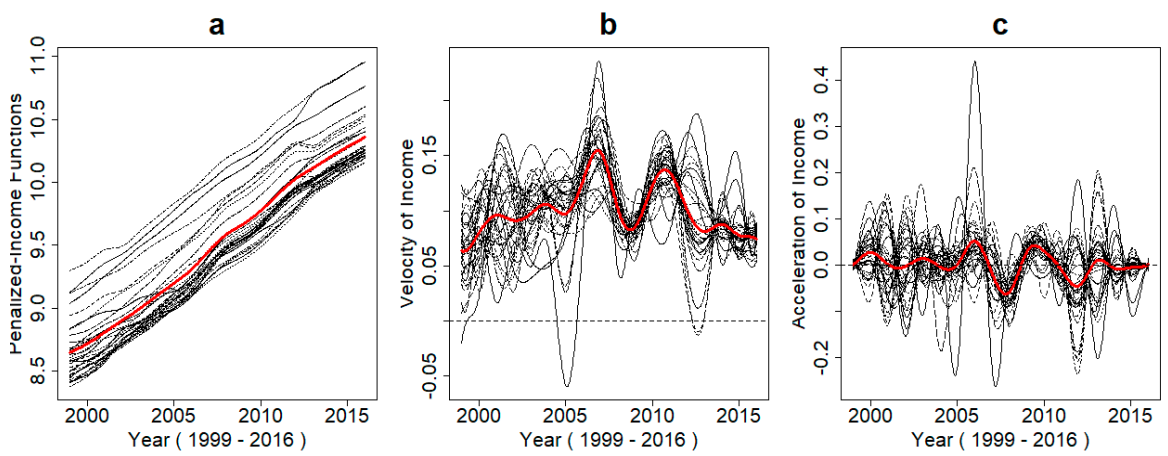

Figure 5. Income functions with first-order and second-order derivatives.

Comparing the curves' trajectories of income and consumption, it can be seen that, except for a few provinces and local fluctuations, the two maintained a synchronous steady growth. The intuitive visualization of the above character is approximate straight-line growth curves, and the smaller roughness corresponded to the smaller penalty smoothing parameter value. By further comparing the trajectories of velocity and acceleration curves in Figures 4 and 5, we can see that, although the static shape features of the income function and consumption function had little differences, their potential dynamic energy transformation differs greatly. Specifically, compared to the roughness of the income function, the velocity and acceleration curve of the consumption function had more peaks and valleys, which could be attributed to more factors affecting urban and rural residents' consumption. In fact, with the improvement of the absolute level of economic development, household consumption was constrained by many factors, such as income composition, consumption concept, price changing, and so on, besides the dominated effect of income.

Figure 6 shows the summary statistics for the functional mean and standard deviation of residents' income and consumption for all regions. It can be seen clearly from panels (a) and (c) of Figure 6, although both of the residents' income and consumption keep a nearly linear growth, the patterns of their standard deviation differed greatly, which were displayed in panels (b) and (d) of Figure 6. The declining trend was common in the standard deviation function of residents' income and their consumption, and both reached their maximum around 2007. It should be noted that the standard deviation of residents' income became smaller after 2007, whereas, the standard deviation trajectory of residents' consumption underwent more rebounds. The above summary statistics is in line with the fact that the growth rate of residents' income in China differed little, while the household consumption rate among different social stratum had obvious disparities $[13,16,26]$.
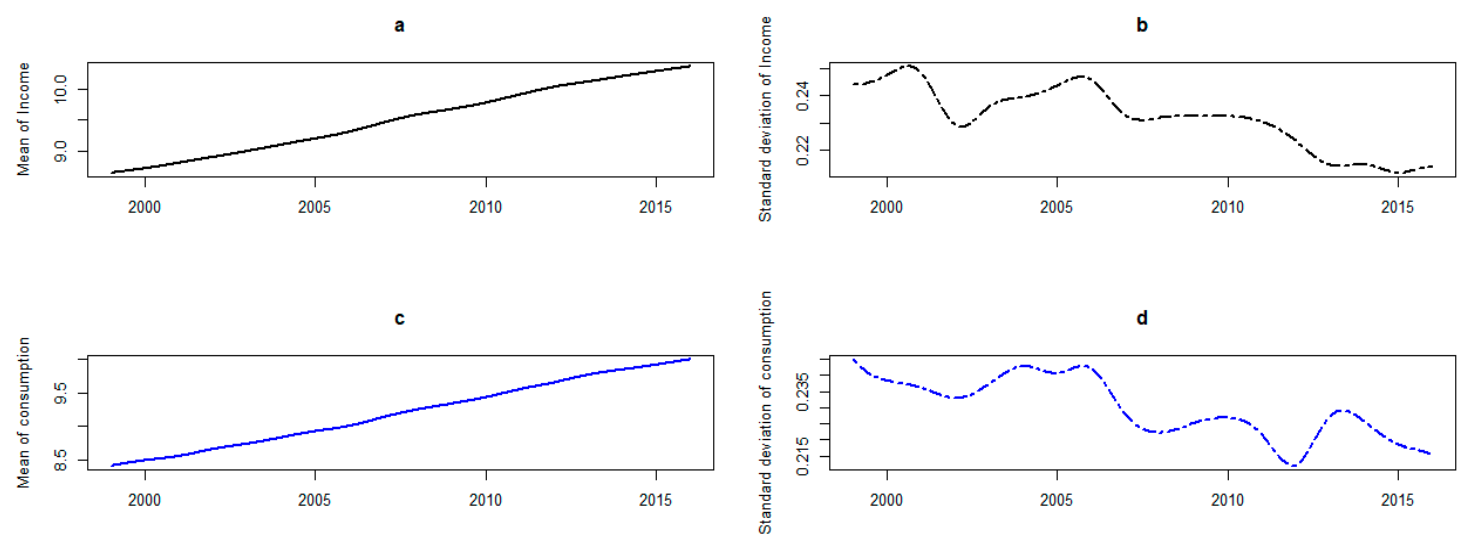

Figure 6. (a) The average of mean and (b) standard deviation for residents' income for all regions. (c) The average of mean and (d) standard deviation for residents' consumption for all regions.

The temporal variance-covariance surface of residents' income and its corresponding contour plots are presented in Figure 7, and Figure 8 displays the analogous summary statistics for the 
functional data of residents' consumption. The concept of variance-covariance surface as well as the corresponding contour in FDA gives new ways to extract information by providing more than a single value or matrix obtained in the traditional univariate and multivariate contexts. We can see from Figures 7 and 8 that the main part of variability occurred around the diagonals, while variability declined elsewhere. Both the highest variability of residents' income and consumption occurred between 2000 and 2007, which was also the period corresponding to the highest standard deviation. The variance-covariance value of residents' consumption was comparably larger than that of residents' income, and the direct reflection is that, there were more peaks in the variance-covariance surface of residents' consumption curves. This could be attributed to the fact that there were more factors influencing residents' consumption besides their income.

a

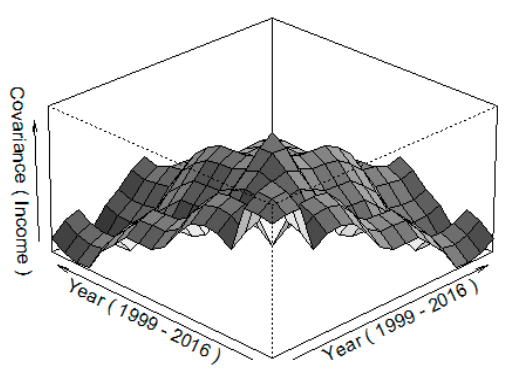

b

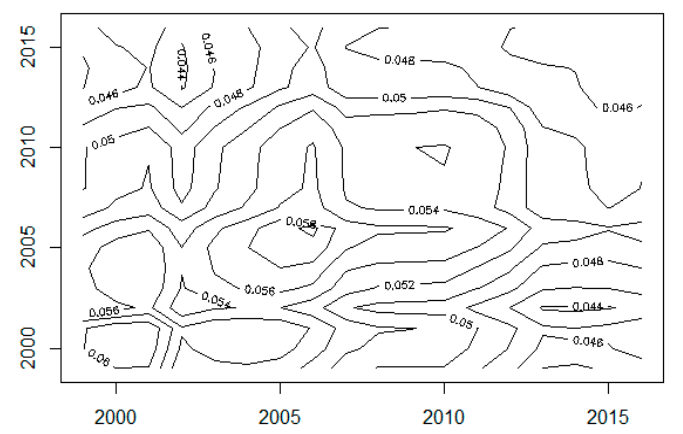

Figure 7. (a) Estimated variance-covariance surface of residents' income curves for the years from 1999 to 2016, and (b) the corresponding contour plot.

In order to confirm whether there are significant differences in income and consumption among China's three major economic zones and to test the robustness of regional differences quantitatively, F-ANOVA based on a 1000-bootstrap sampling was conducted on original functions and their velocity and acceleration, respectively. Figures 9-11 present the test results of the consumption function. The same procedure was performed on the income function, and the results are displayed in Figures 12-14.

a

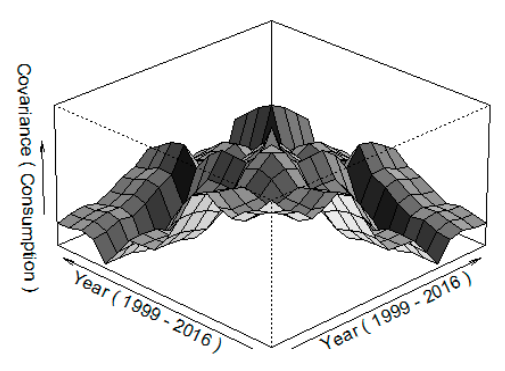

b

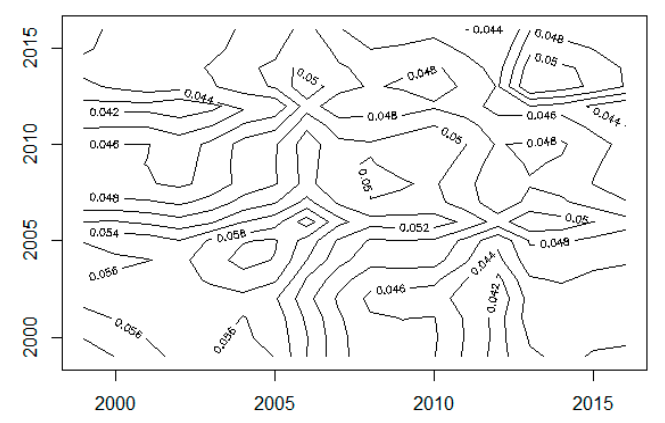

Figure 8. (a) Estimated variance-covariance surface of residents' consumption curves for years from 1999 to 2016, and (b) the corresponding contour plot. 

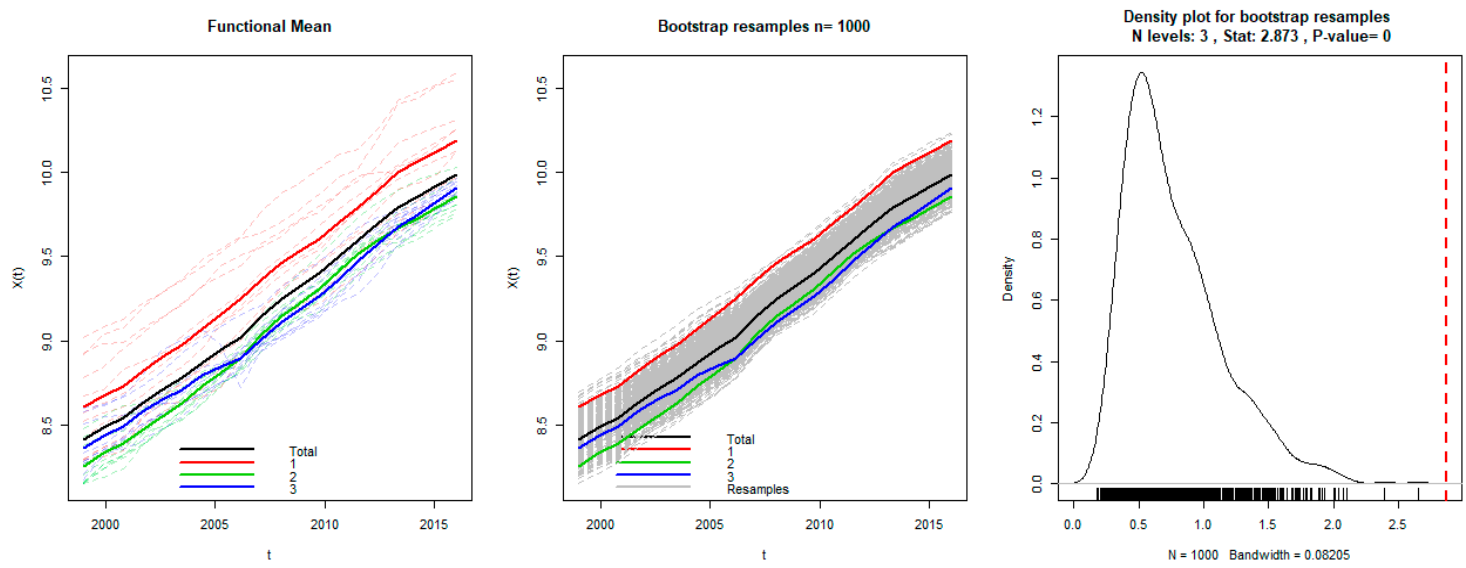

Figure 9. F-ANOVA test for regional differences of consumption.
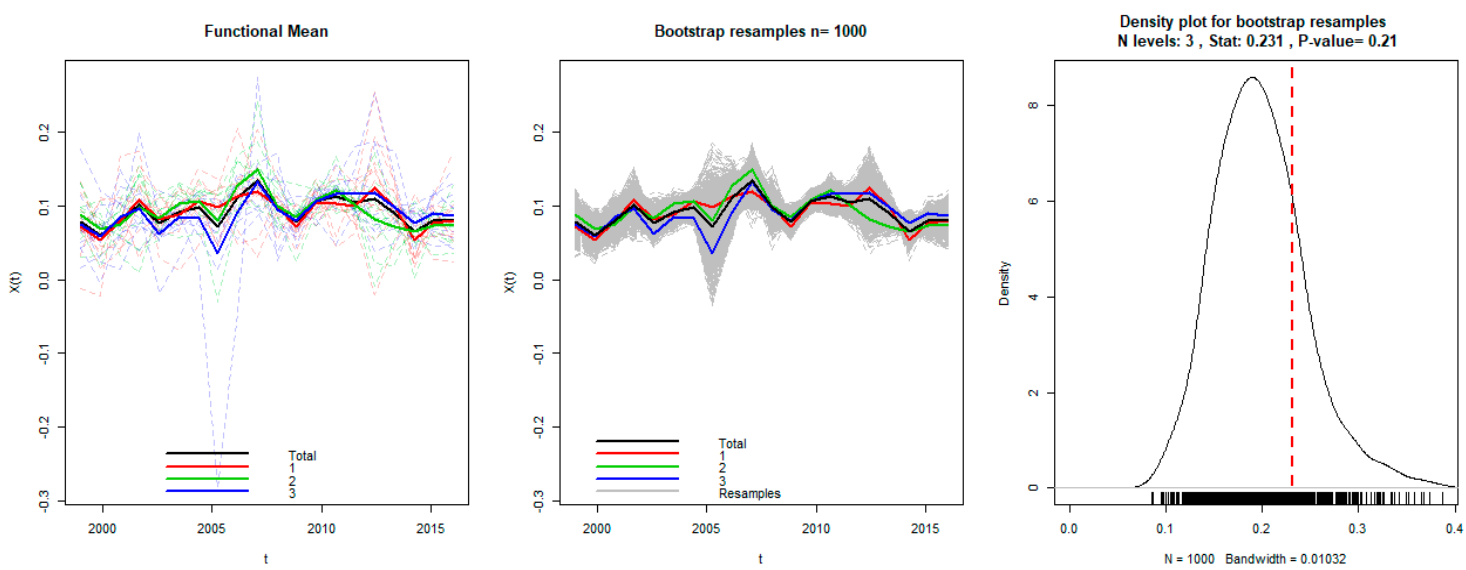

Figure 10. Difference test based on F-ANOVA for velocity of consumption.
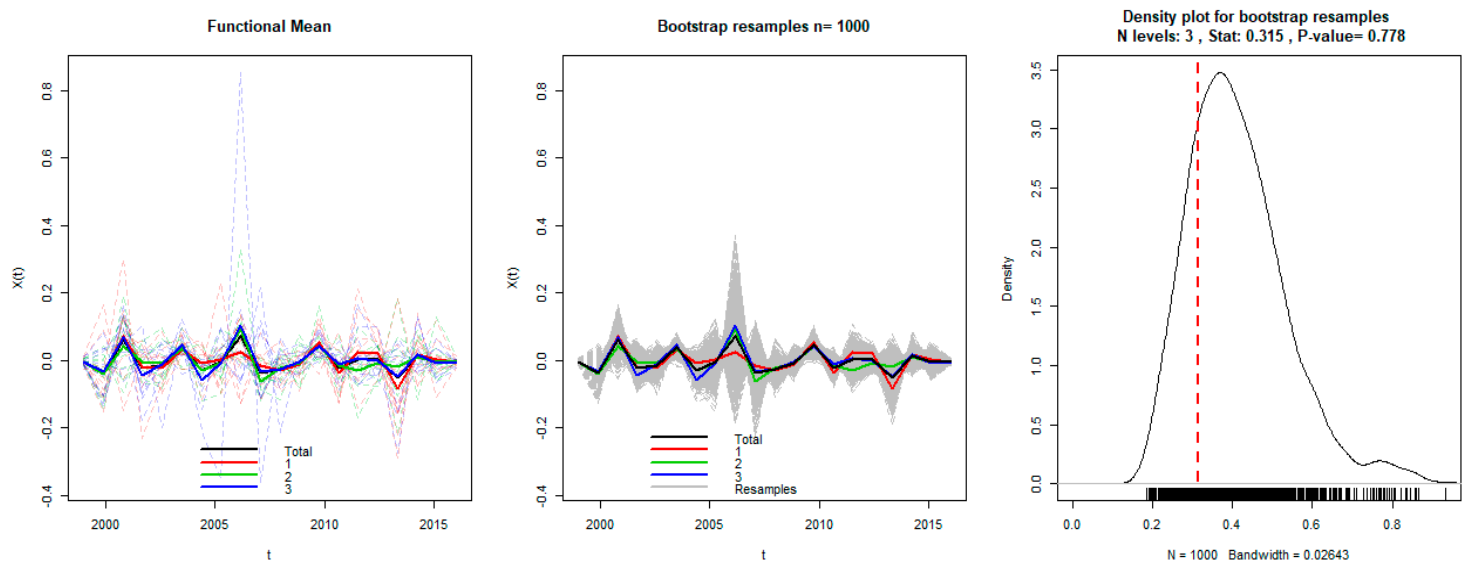

Figure 11. Difference test based on F-ANOVA for acceleration of consumption. 

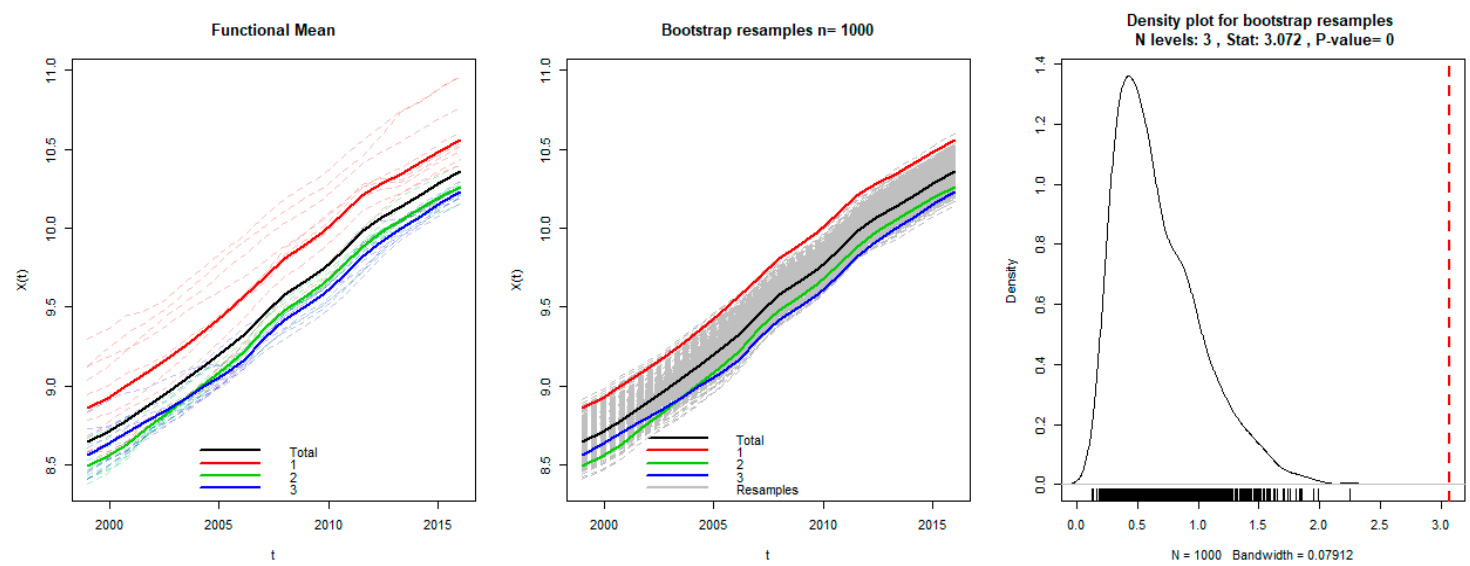

Figure 12. F-ANOVA test for regional differences of income.
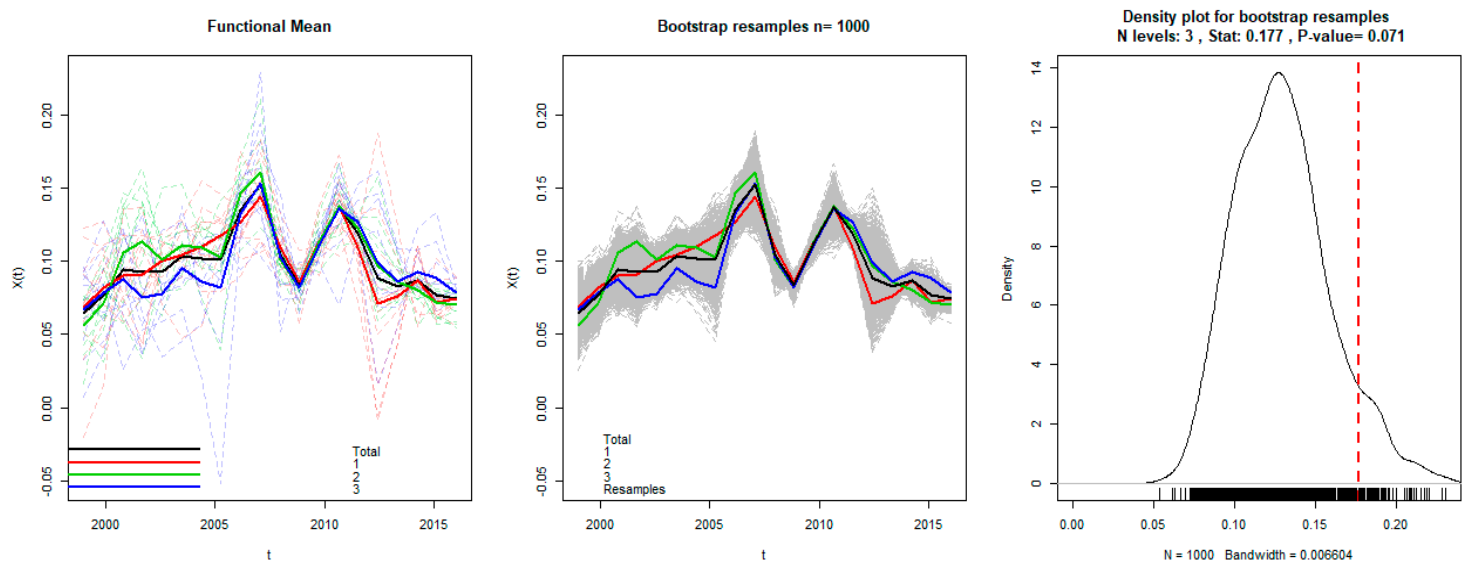

Figure 13. Difference test based on F-ANOVA for velocity of income.
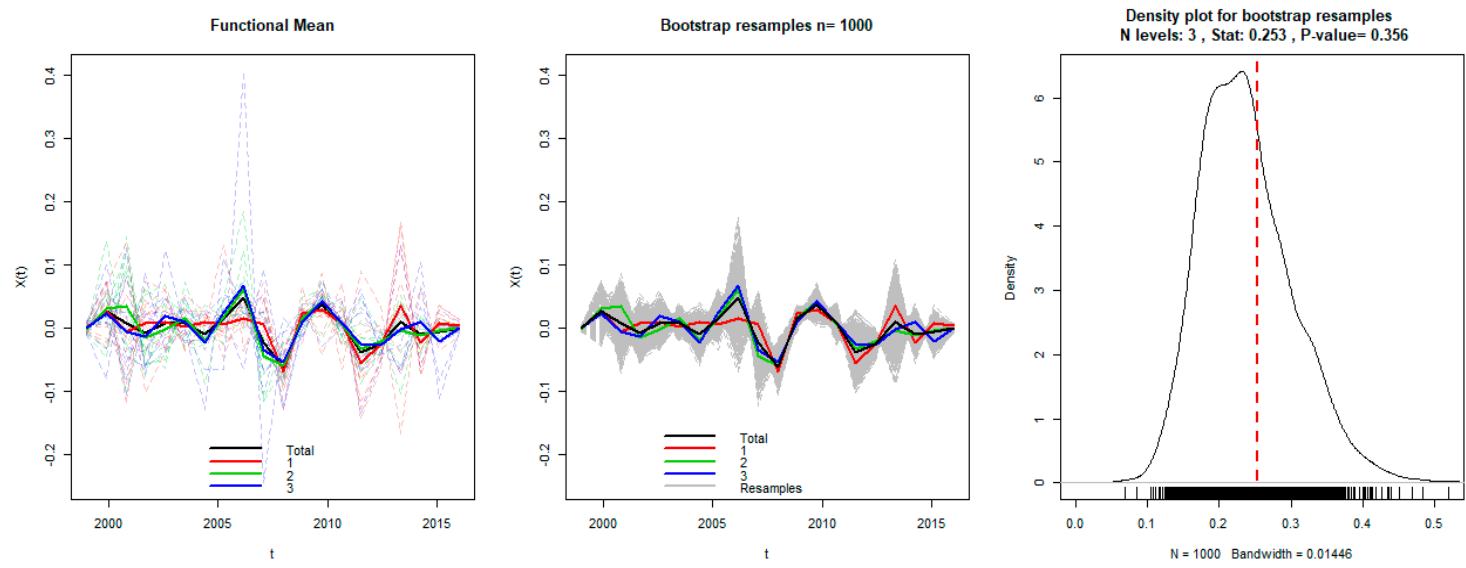

Figure 14. Difference test based on F-ANOVA for acceleration of income.

According to the test results of F-ANOVA in Figures 9-14, we can see that there were significant regional differences among the three major zones of China at the static level, both in the income function and the consumption function, which is consistent with the permanently stable disparity in the absolute level between their mean functions. As a visual representation of the above differences is the approximate parallel linear growth trajectories of the mean function in different zones, shown in the left panel of Figures 9 and 14. Although the initial absolute level of income and consumption among the eastern, middle, and western zones differed significantly, the differences in velocity and acceleration did not pass the significance test at the level of 0.05 , which indicated that the potential of dynamic 
growth among the three major economic zones did not have distinct regional disparities. Upon the comprehensive summary of the test results from Figures 9-14, it was not difficult to determine that the current income imbalance between urban and rural residents and regional consumption disparity in China resulted from the initial level and structure; there was no distinction in the regional growth potential of income and consumption. As a result, the Chinese government need not take into account regional influence factors too much when implementing policies to boost income and stimulate consumption.

\subsection{Phase Analysis of Energy Transferring of Income and Consumption}

Although the overall trend in the dynamic changing of income and consumption functions among the three economic regions of China from 1999 to 2016 did not have any significant difference, the law of potential energy transferring of income and consumption functions in different zones have their own particularity. In order to compare the phase-plane characteristics of income and consumption and their spatial differences in potential energy transference, we used graphical techniques to study how derivatives related to another, which is called phase-plane plotting [41]. Taking velocity as the abscissa and acceleration as the ordinate, the countrywide and three regional phase-plane plots of income function are presented in Figure 15, and Figure 16 displays the similar phase-plane plots of consumption function.
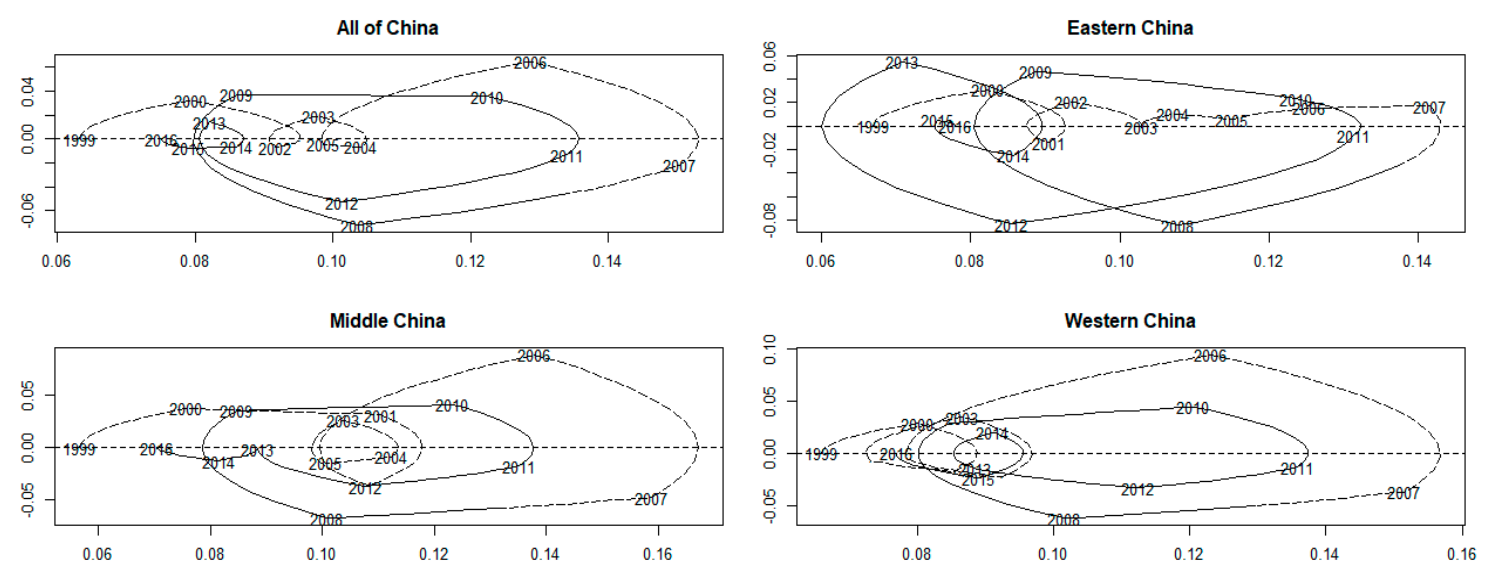

Figure 15. Phase-plane plots show energy transfer of income function.
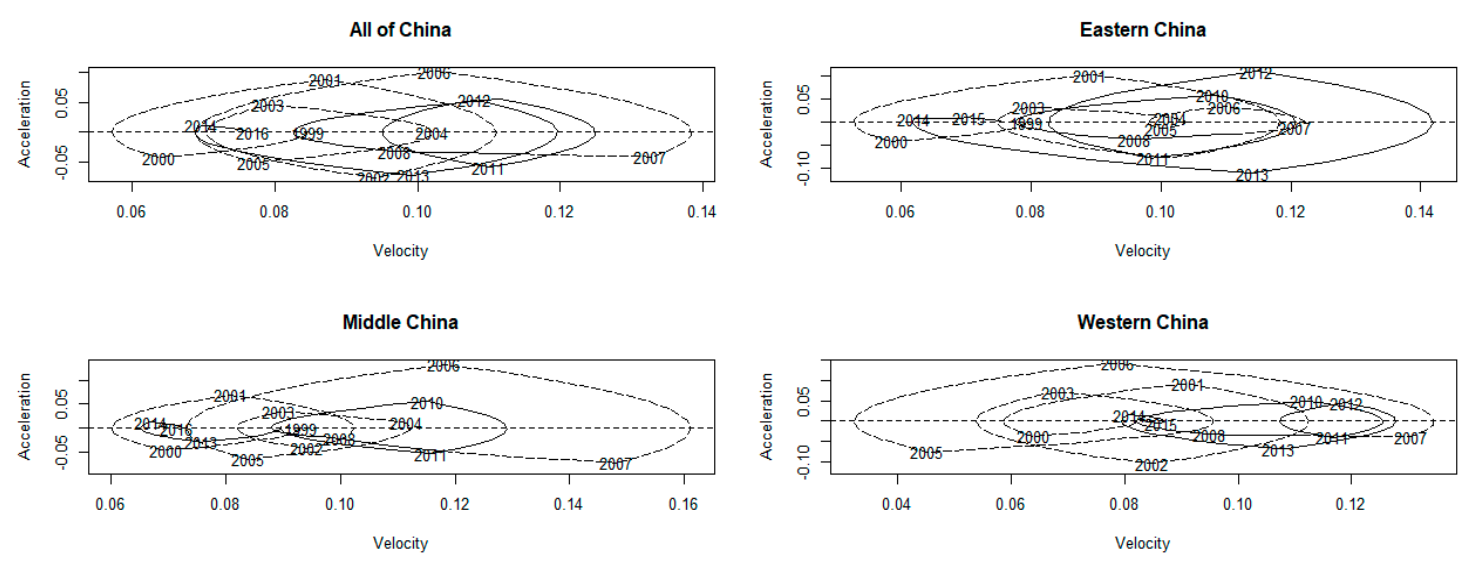

Figure 16. Phase-plane plots show energy transfer of consumption function.

Taking the countrywide phase-plane plots as a comparison benchmark, all the transference trajectories of potential energy of income and consumption functions went through more than five cycles, and the velocity of growth kept positive all the time, while the acceleration of growth fluctuated around 0 . The above results indicated that the income and consumption of the three major economic 
zones experienced multiple rounds of growth during the research interval. Although the absolute level maintained positive growth, the amplitude, speed, and duration of growth showed obvious distinctions. Specifically, the vertical amplitude and horizontal phase of income and consumption in the western region were the largest, which indicated that the initial level of income and consumption in the western region was relatively low, while the larger growth rate and amplitude reflected more room for improvement. Between 2006 and 2007 was the largest interval of velocity and acceleration, both for income and consumption in the middle and western regions. The reason for this result is probably traceable in part to the cancelling of compulsory educational children's school tuition and fees by the State Council of the People's Republic of China. Cancelling the compulsory educational children's school fees was first launched by the middle and western regions in 2006 and extended to the eastern region in 2007 (MOE of PRC, 2008) [44]. The cancelling of tuition and fees was jointly committed by central authorities and local fiscal revenue, which drastically loosened expenditure constraints for residents in the middle and western regions and further stimulated residents' consumption demand. Compared with the middle and western economic zones, there was no obvious change in the patterns of potential energy transfers for both income and consumption from 2006 to 2007 in the eastern region. The reason for the above is the absolute level of residents' income in the eastern region had already broken through the expenditure restriction of compulsory education. By the end of 2016, the growth velocity and acceleration of residents' income and consumption functions in the three major zones were basically the same, which proves once again that there was no regional difference in the dynamic growth potential of income and consumption of urban and rural residents in China.

\subsection{Functional Canonical Correlation Analysis for Residents' Income and Consumption}

In order to visually display the dynamic features of global correlation between the residents' income function and the consumption function, the three-dimensional surface of the cross-correlation function between the two and their contour plots are shown in Figure 17. According to the data indicated by the contour lines, the degree of correlation between the income function and consumption function was within the range of 0.82-0.96. The maximum correlation coefficient was distributed symmetrically on both sides of the diagonal line, and the degree of correlation decreased when the separated years increased. The above statistical characteristics of the correlation function indicated that residents' current income was the determinant factor that restricted residents' consumption, but residents' income in the previous period still had a large influence on the current consumption. As a result, residents can rationally adjust consumption time, level, and structure according to the expected changes in their income.
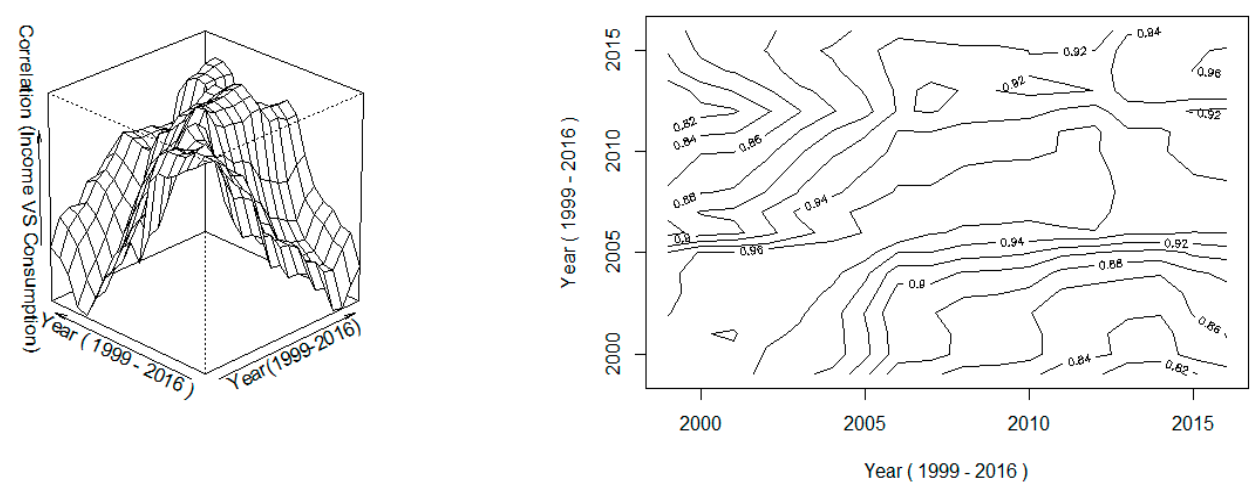

Figure 17. Surface and contour of cross-correlation functions of income and consumption.

The FCCA was conducted between income functions and consumption functions to extract patterns of dynamic correlation and their temporal characteristics. Meanwhile, in order to avoid difficulties in explaining the trajectories of weight functions for their high-frequent fluctuations, we select different values between $10^{-9}$ and 0 to smooth the weight functions, and found that the 
changes in smoothing parameters had little effect on the overall variability structure. Thus, the same value of $\kappa=10^{-9}$ in Section 4.1 was selected as the roughness penalty parameter. The first six FCCA values related to income and consumption are presented in Table 1. It can be seen that the last FCCA values were obviously small when compared to the first three, which indicated that the core information of the FCCA was concentrated in the first three weight functions. Thus, this study mainly discusses the first three canonical variables. The dynamic trajectories of the first three FCCA weight functions are displayed visually in Figures 18-20.

Table 1. Smoothed FCCA values.

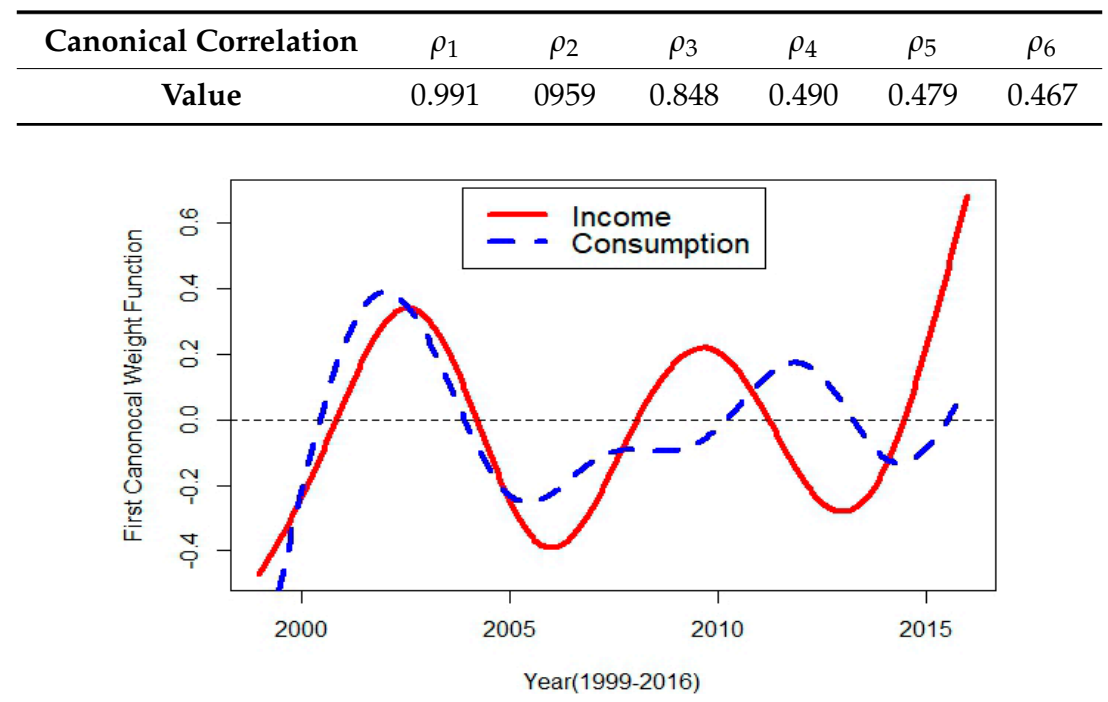

Figure 18. First FCCA weight functions.

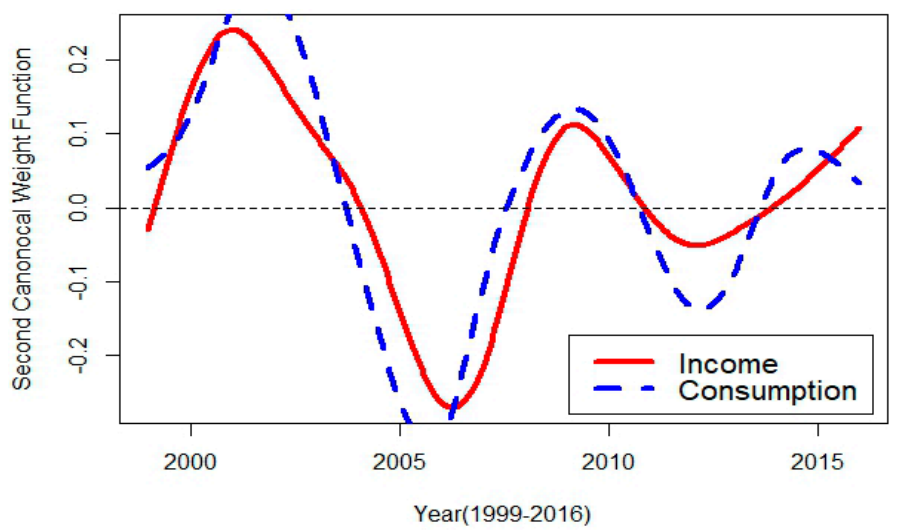

Figure 19. Second FCCA weight functions.

By comparing the fluctuation trajectories of the three pairs of weight functions, we found the whole patterns of the curves' fluctuations had high similarities, although the time points of the peaks and valleys appeared to be different. Specifically, the amplitude of longitudinal fluctuation showed a decreasing trend, which was consistent with the order of the correlation values corresponding to the three pairs of weight functions. There were more peaks and valleys in the curve of weight function that correspond to residents' consumption, which could be attributed to more factors affecting consumption decisions. As seen from the first pair of FCCA weight functions, both curves corresponding to income and consumption had approximate vertical amplitudes for this time span. Additionally, the peak and valley of the weight function corresponding to consumption occurred slightly earlier than that of income before 2007, but their leading order reversed after a short-term adjustment in 2007, with earlier points and a larger amplitude in the weight function corresponding to income. The above 
evolution process indicated that the changes in consumption lagged behind that of income until 2007, and then the leading order reversed, but the influence intensity between consumption changes and income changes was roughly the same. The reason for this finding may result from the fact that the growth of Chinese residents' consumption has lagged behind the growth of fixed asset investments since 2000, thus lagging behind the growth of gross national product and residents' income [45]. However, influenced by a series of reforms from 2005 to 2007 in the education funding guarantee mechanism, the relaxation of income restrictions on residents' consumption had stimulated residents' total consumption demand. However, a necessary process was required for residents to change their consumption behaviors and habits, so there was a long time lag in the transmission of the consumption growth effect on economic growth and residents' income growth.

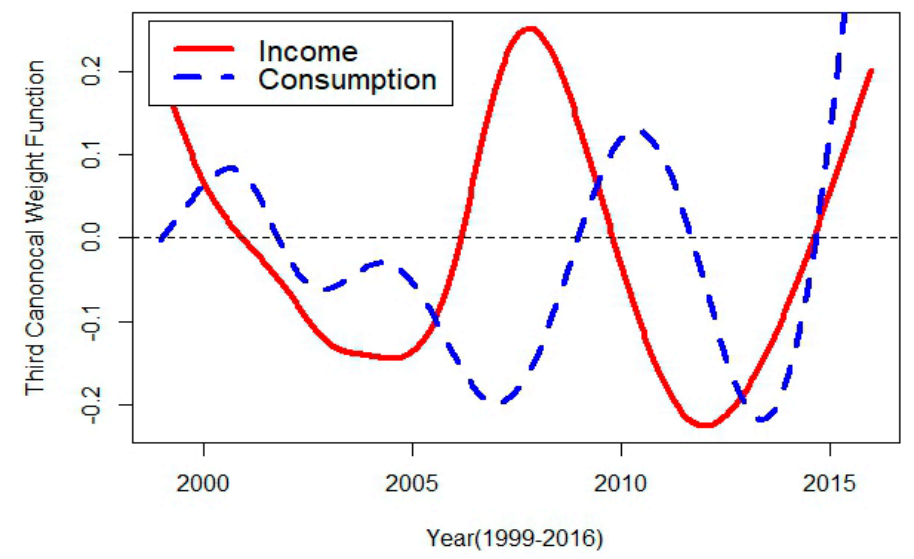

Figure 20. Third FCCA weight functions.

Except for a smaller co-varying lag, the change pattern of the second pair of FCCA weight functions was approximately the same as that of the first pair of FCCA weight functions, but the fluctuation amplitude of the weight function corresponding to consumption was larger, indicating that the consumption growth was less than the income growth, which is consistent with the law of marginal propensity to consume lying between 0 and 1 . As for the third pair of FCCA weight functions, the value of the weight function corresponding to consumption was kept larger until 2006, and it underwent one more peak-and-valley periodic fluctuation, maintaining a downward trend. Then, the consumption change was ahead of the income change after 2006. The reason for this result was because the final consumption rate and residents' consumption rate showed a decreasing trend jointly year by year in China since 2000, according to the data analysis of National Bureau of Statistics from 2000 to 2017. Although the government promulgated a series of policies to stimulate consumption, it did not curb the declining trend of consumption fundamentally [46]. The depressed situation lasted until 2007, when the Central Committee and State Council of China adopted reformations to improve the distribution structure of national income and made unprecedented efforts to reinforce the social security system and people's livelihood projects. Stimulated by the aforementioned multiple measures, residents' consumption showed a faster growth momentum, and the consumption growth was ahead of income growth.

In order to further analyze the relationship between the degree of canonical correlation of different provinces and their geographical locations, the FCCA scores $\left(U_{k}, V_{k}\right)$ from three pairs of weight functions for 31 provinces were drawn, as shown in Figures 21-23. 


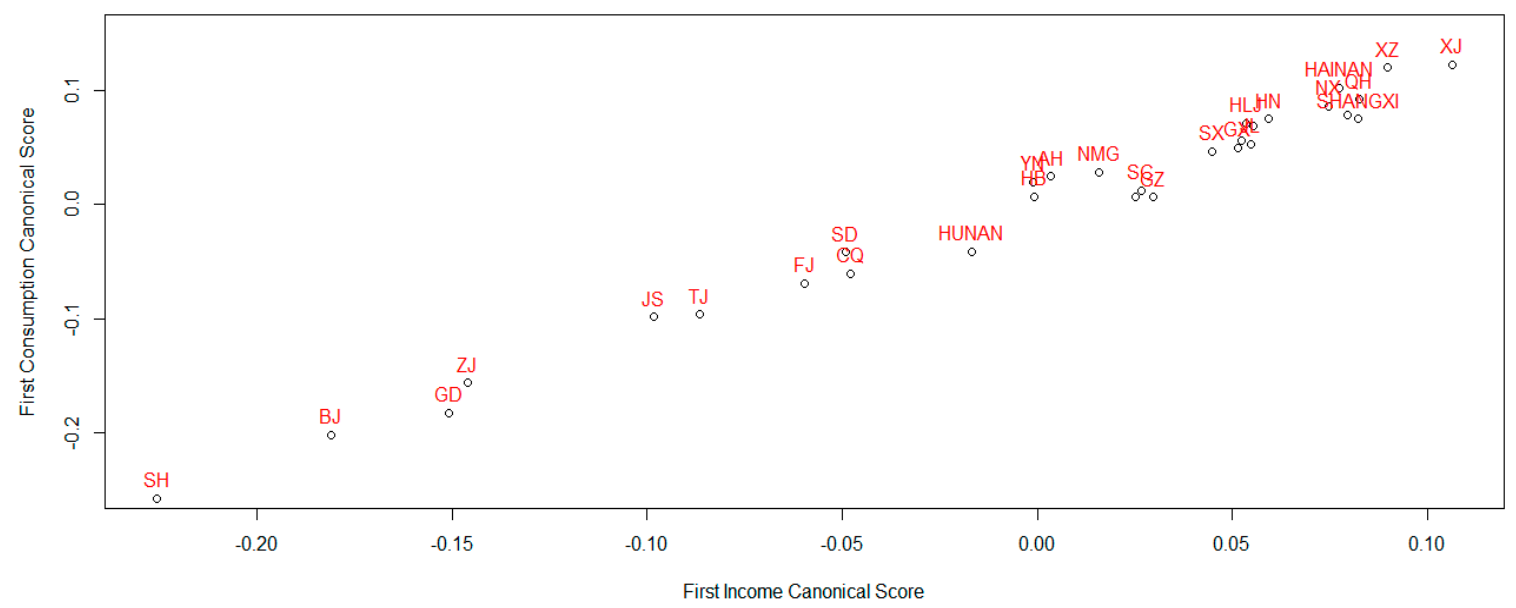

Figure 21. FCCA scores from the first pair of weight functions.

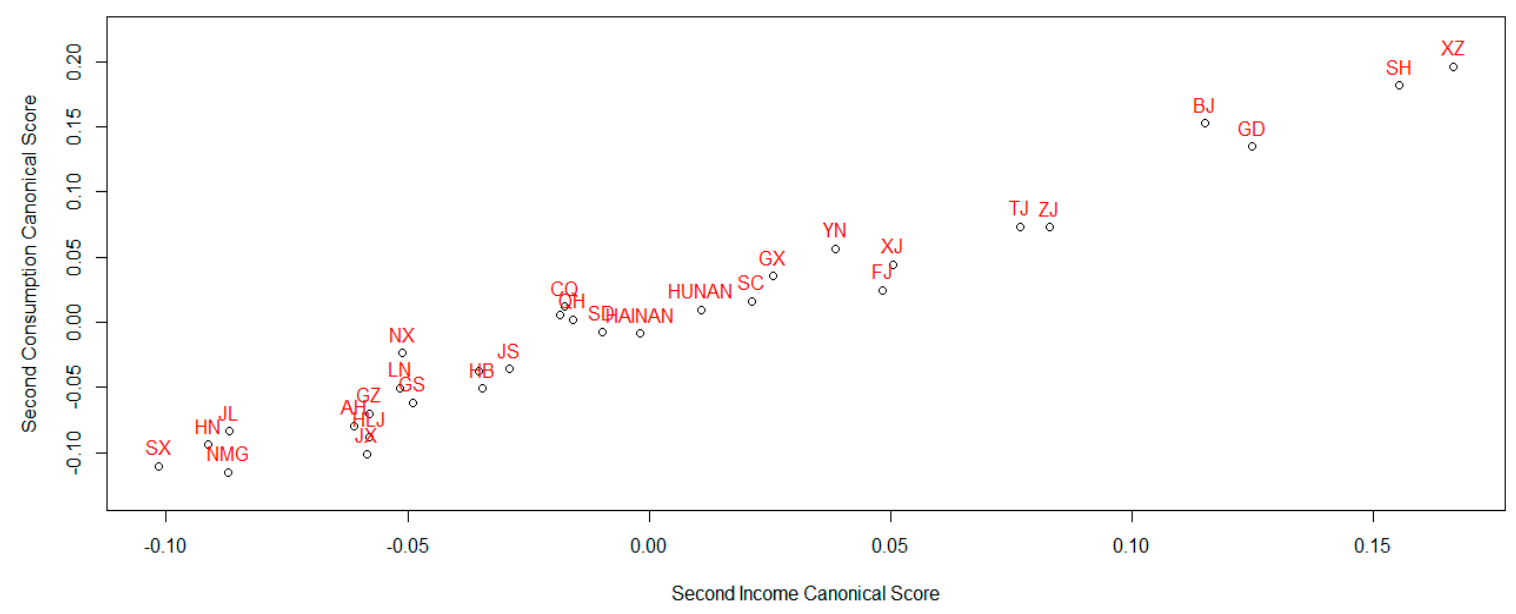

Figure 22. FCCA scores from the second pair of weight functions.

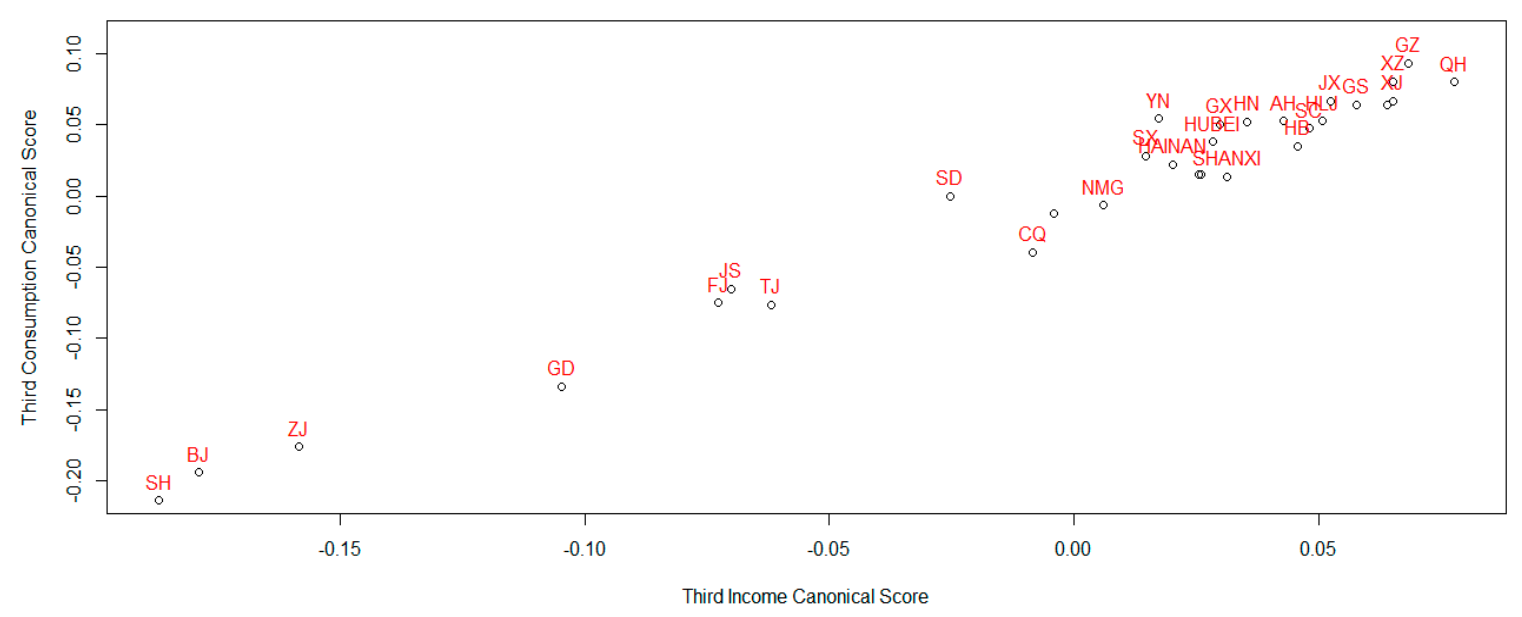

Figure 23. FCCA scores from the third pair of weight functions.

Comparing the scatter plots of the scores from three pairs of weight functions, we found that all three scatter plots showed a near-linear relationship, indicating that the correlation between income and consumption was high, which is consistent with the leading FCCA values in Table 1. However, there was a certain regularity in the scores gathered for different provinces with respect to their geographical locations. Specifically, the provinces of the eastern zone were scattered dispersedly in the lower-left corner of Figure 21, and Shanghai, Beijing, Zhejiang, and Guangdong were the 
first four provinces with the lowest scores on the first weight functions, which indicated that the degree of canonical correlation between income and consumption in the eastern zone was relatively low. In contrast, the provinces of the middle and western zones were gathered densely in the upper right corner, indicating that the canonical correlation between income and consumption in those zones was high. The reason for this finding lies in the fact that income is always the determining factor of consumption at any level; thus, they maintain a positive coordinated change. However, the educational resources and the absolute income level of the eastern region were far more than that of the national average, and the marginal propensity to consume had a diminishing character. Together, the above factors led to a higher stimulating effect in the middle and the western zones than that in the eastern zone when implementing policies, such as the reform of the educational funding guarantee mechanism. As the scatter plot of the second FCCA score in Figure 22 shows, both FCCA scores of income and consumption closely correspond to their economic development level in almost all provinces, except Tibet. Inferred from the synchronous change characteristics of their weight functions in Figure 19, the absolute growth of income and consumption mainly depended on their economic development level. Although there is a large gap between the absolute growth of income and consumption in each period among different economic zones, the relative growth of the middle and western zones maintained a higher positive correlation change due to the initial lower development level and the homogeneous residents' consumption structure. As a visual reflection in Figure 23, the third FCCA scores were densely located in the upper right corner. It should be noted that, in Tibet, as a special case, there was a highly positive correlation regarding its initial level, absolute growth rate, and relative growth rate, which was closely related to its special central financial subsidy and aid policies.

\subsection{The Dynamics of Residents' Income and Consumption}

Although the growth trajectories of residents' income and consumption differ little, the results of the F-ANOVA test in Section 4.1 indicated that the velocity and acceleration between the two have significant difference. To capture the dynamic difference in their coevolving process, principal differential analysis was performed. Determining the specific formula of dynamic models required comparing the fitting results of different order differential equations with a consideration of the trajectories of curves. Due to the approximate linear growth trends of logarithmic income and consumption, which can be seen from the curves' trajectories in Figures 2 and 3, and from a model parsimony standpoint, the second-order varying coefficient homogeneous differential equation was adopted [47]; that is, $L f(t)=\beta_{0}(t)+\beta_{1}(t) D f(t)+D^{2} f(t)=0$. Figure 24 shows the residual functions $\varepsilon(t)$ resulting from applying the equation for residents' income and consumption function. The fit was especially close in the middle, with only a short interval at the beginning and end that did not seem to be captured equally as well by the PDA model. In order to further assess the adequacy of the model fitting, goodness of fitting for different order differential equation models was calculated. The comparison of different pointwise $\mathrm{R}^{2}$ indicated that the goodness of fit clearly improved when the order of the differential equation changed from zero to two, but the fits of the higher order differential equation above the second order did not increase significantly. The detailed fitting values we obtained were $0.473(0.425) \rightarrow 0.862(0.833) \rightarrow 0.944(0.937) \rightarrow 0.946(0.951)$ when the order of differential equation changed from zero to the fourth, indicating the second order homogeneous differential equation was a sufficiently good model for fitting the dynamics of residents' income and consumption. The estimated functional coefficients $\beta_{0}(t)$ and $\beta_{1}(t)$ are presented in Figures 25 and 26, respectively. 


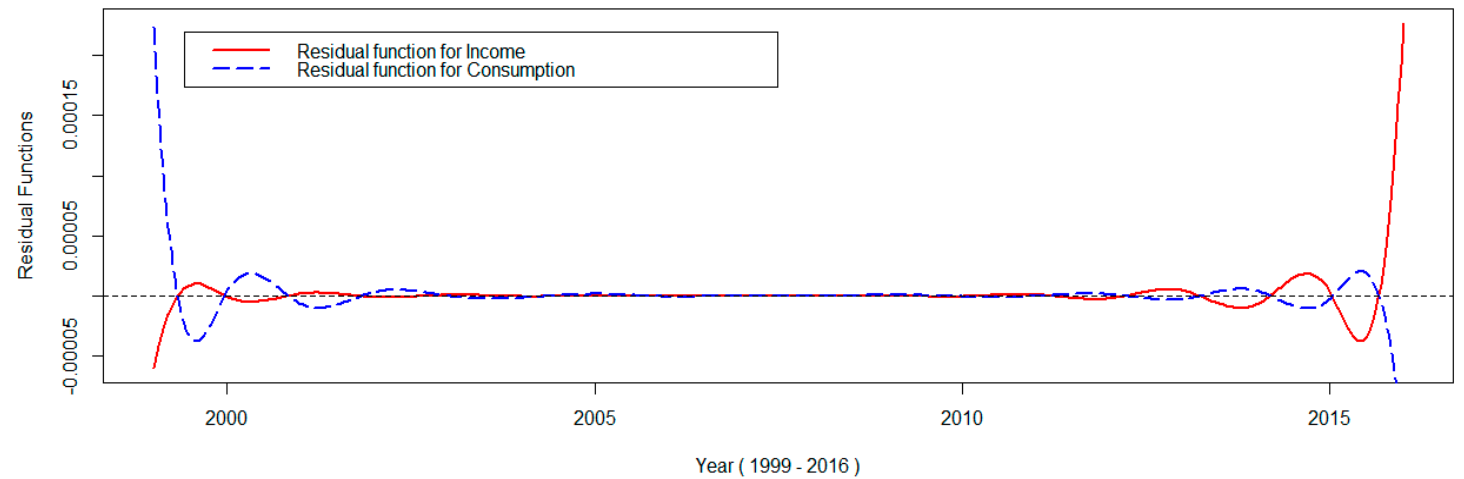

Figure 24. The residual functions $\varepsilon(t)$ for residents' income and consumption.

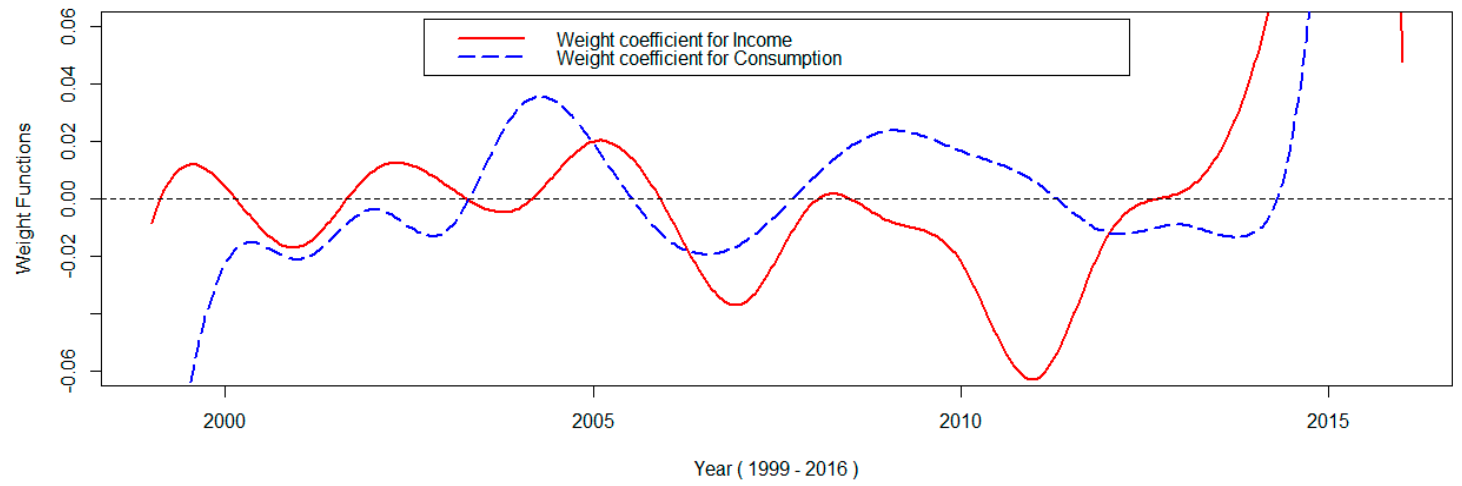

Figure 25. The estimated functional coefficients $\beta_{0}(t)$.

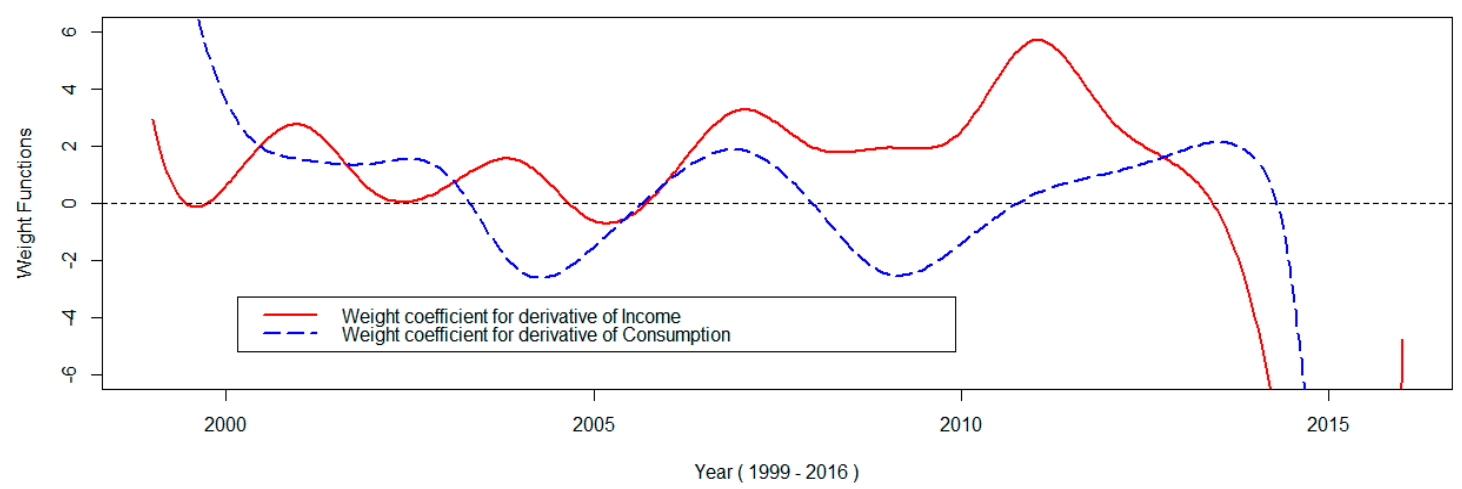

Figure 26. The estimated functional coefficients $\beta_{1}(t)$.

As pointed out by Ramsey et al. (1996) [40], the first coefficients, $\beta_{0}(t)$, essentially reflect the position-dependent oscillation. The second coefficients, $\beta_{1}(t)$, however, result from exponential growth or decay. We make a comparison with the trajectories of $\beta_{0}(t)$ and $\beta_{1}(t)$, and found that both the coefficients exhibited a fluctuation around zero, which was consistent with the approximately linear growth trend of logarithmic residents' income and consumption. Specific to $\beta_{0}(t)$, both the trajectories of residents' income and consumption maintained fluctuations with the same frequency, except for a few time-lags, which proved again the dominant influence of residents' income on their consumption. What was more, the size of oscillation becoming larger since 2003, which can be proved by the actual data characteristic of residents' income on consumption [42]. The comparison of $\beta_{1}(t)$ trajectories indicated that residents' income maintained an exponential growth on the whole, while residents' consumption did not maintain an exponential growth trend, an even appeared to exponentially decay in some years. The oscillation difference between residents' income and consumption, which were exhibited by the trajectories of $\beta(t)$, was consistent with residents' increasing growth of total income 
and their declining consumption rate $[13,16,29,48]$. The dynamic analysis of residents' income and consumption implied that although China's rapid economic growth had benefited the growth of household income, the substantial increase in absolute income did not make a qualitative difference in household consumption. The empirical result proved the existent disparity of different social strata that groups of high income have a low consumption rate and groups of low income cannot afford to spend. As a conclusion, to promote the household consumption rate of China, governments should place an emphasis on optimizing the redistribution of national income, increasing residents' stable disposable income, and guiding residents to change their consumption concept and consumption structure.

\section{Discussion and Conclusions}

Based on the current division of three economic zones in China, this study incorporated the discrete noisy data of residents' income and consumption into the framework of functional data analysis. Functional ANOVA was adopted to test the regional differences between Chinese residents' income and consumption, both from the static and dynamic interactive perspectives. The temporal characteristics of their coevolving processes and dynamic changes from 1999 to 2016 were captured via PDA. The conclusions of this study are as follows.

(1) There were significant regional differences in the initial absolute level of residents' income and consumption among the provinces in the eastern, middle, and western zones, but the differences in velocity and acceleration of income and consumption growth among the three regions was not significant. The relevant literature has provided evidence that there existed disparity in absolute level of residents' income and consumption [49-51]. In fact, as a typical dual economic structure, the unbalanced development among different regions in China was the joint result of complex factors such as different industrial structures and distinct economic policies. Until now, as a long-term accumulated result, the absolute level gap of income and consumption has not yet been fundamentally reversed [52,53]. However, with the continuous improvement of China's economic development, the equalization of fiscal redistribution, and the gradual transformation of residents' consumption concept, the growth of residents' income and consumption in different regions has been converging [54,55]. Different to the previous conclusions derived from econometric analysis on the absolute level of residents' income and consumption, we quantitatively confirmed the fact that there was no regional difference in the growth potential of residents' income and consumption from the interactive perspectives of velocity and acceleration. The economic implications of the above conclusion is that, although the absolute disparity between the three economic zones is still large, governments need not consider regional factors too much when implementing policy of stimulating residents' consumption to expand domestic demand.

(2) No matter the static absolute growth level or the dynamic growth potential energy, residents' income and consumption always maintained a highly positive canonical correlation, which means that residents' income was the decisive factor that restricted their consumption level and structure, and the stimulation of consumption had a significant effect in promoting regional economy and residents' income. In addition, the value size and sequence of nonlinear evolution of FCCA weight functions had obvious temporal characteristics. It is a well-known fact that residents' income is the dominant factor influencing their consumption, and a large amount of literature has verified that the relationship between residents' income and their consumption exhibited various patterns of fluctuation, such as structural breaks [55,56] and a phenomenological law [48]. The economic implications of our empirical result is that the specific period of coevolving between residents' income and consumption should be taken into consideration when the government formulates or implements policies to reduce income gaps and stimulate consumption.

(3) There were significant regional differences between the functional canonical correlation scores of residents' income and consumption. The relatively rapid level of economic development resulted in a higher canonical correlation between the absolute growth of residents' income and consumption in the eastern zone. The initial low level of economic development and homogeneous structure of 
consumption led to a higher degree of functional canonical correlation between the relative growth of residents' income and consumption in the middle and western zones. Although the absolute growth of income and consumption in the eastern zone was relatively large, the growth potential of the middle and western zones was even greater. In fact, nonlinear test results show that the stimulating effect of residents' income on their consumption in China exhibited an inverted " $U$ " shape, the eastern regions and the country was in the downstream region, and the middle and western regions was in the upward area [57]. Our empirical result was in line with the above conclusion, that is the stimulating effect of residents' income on their consumption in eastern regions decreasing, while the marginal stimulating effect in middle and western regions stayed positive. The economic implications of our empirical result is that the effective method for solving the shortage of domestic demand is strengthening the adjustment of fiscal revenue redistribution in the middle and western regions, and increasing the supply of public services in underdeveloped areas to release residents' income liquidity constraints for consumption.

(4) Although the absolute levels of Chinese residents' income and consumption have raised substantially due to the rapid economic growth, the long-term depression of household consumption did not change fundamentally. The above conclusion was derived from the trajectory of $\beta_{1}(t)$ in the PDA for residents' consumption, which fluctuated around 0 with a fairly small range. Actually, the consumption structure of residents in China has significant disparity between different social stratum [58]; that is, the middle and upper-income groups were unwilling to consume, while the permanently low income level limited low-income groups' consumption. Therefore, the government should focus on promoting residents' consumption rate when formulating and implementing policies to expand domestic demand. The key to solve the problem of insufficient domestic demand in China may rely on strengthening the adjustment of income distribution in the middle and western regions. The low consumption level of low-income residents will directly lead to their quality of life lagging behind that of high-income residents. Considering that public service, such as medical care and education, play an increasingly important role in the modern national economy, and the provision of public service should incline towards providing for the impoverished social class and undeveloped areas so as to remedy the deficiencies of public resources due to the income gap, thereby improving the level of social welfare for all residents.

Compared with the existing literature, this paper is among the first efforts to introduce functional data analysis, a big data analytical method, to study the spatial and temporal differences in the relationships between residents' income and consumption in China. This paper is of significance for both empirical methodology and important policy implications. First, we quantitively proved the fact that there existed a significant disparity in the absolute level of residents' income and consumption between the three economic zones in China, while the difference in their growth potential was not statistically significant. We derived the above conclusion via functional ANOVA of residents' income and consumption, both statically and dynamically. Second, our findings are important for the Chinese policymaking concerning the expansion of domestic demand and the society's fair and stable development. China is trying to find an endogenous growth of the economy, where the key premise is to stimulate residents' consumption. However, there is no effective policy to increase their consumption substantially due to the long-standing income gap and precautionary saving. Based on the findings of this paper, the government should strengthen the GNP redistribution to increase the per capita disposable income in underdeveloped areas. Furthermore, the government should provide more public services and improve the social security system in rural China.

The main contribution of our study is focused on how the FDA techniques can be used for residents' income and consumption analysis. Instead of utilizing discrete income and consumption data, we can create a functional form for the data, which could be analyzed over any time interval. Besides, we can mine dynamic information from the interactive derivatives of the smoothing income and consumption functions, which is powerless for traditional econometric methodologies. Therefore, our work enriched the toolbox of human geography and social sustainability research. As a future 
research direction, we will employ more FDA techniques, under the light of relevant economic theories about the determinants of consumption patterns, to study the convergence of income and consumption for different social strata.

Author Contributions: Conceptualization, D.W. and L.H.; Methodology, D.W.; Software, D.W.; Validation, Y.X., R.L. and L.H.; Formal analysis, Y.X.; Investigation, Y.X.; resources, Y.X.; data curation, R.L.; writing-original draft preparation, D.W.; writing - review and editing, L.H.; visualization, Y.X.; supervision, L.H.; project administration, D.W.; funding acquisition, Y.X. and L.H.

Funding: This study was supported by the Fundamental Research Funds for the Central Universities (Project nos. 2015WA01).

Acknowledgments: We thank the editor and anonymous referees for helpful comments. All errors are our own.

Conflicts of Interest: No potential conflict of interest was reported by the authors.

\section{References}

1. Keynes, J.M. General theory of employment, interest and money. Am. Econ. Rev. 1936, 26, 490-493.

2. Kuznets, S. Economic growth and income inequality. Am. Econ. Rev. 1955, 45, 1-28.

3. Anand, S.; Kanbur, R. The Kuznets process and the inequality development relationship. J. Dev. Econ. 1993, 40, 25-52. [CrossRef]

4. Liu, Y.; Zou, W. Rural-urban migration and dynamics of income distribution in China: A non-parametric approach. China World Econ. 2011, 19, 37-55. [CrossRef]

5. Wen, T.; Tian, J.H.; Wang, X.H. Research on the overall influence of farmers' income structure on consumption structure and regional differences. China Soft Sci. 2013, 3, 42-52.

6. Wang, X.H.; Wen, T. Research on the differences between urban and rural residents' consumption behavior and structural evolution. J. Quant. Tech. Econ. 2015, 10, 90-107.

7. Wang, X.H.; Wen, T.; Zhu, J. Study on the formation of habits, imbalance of income structure and evolution of rural residents' consumption behavior. Econ. Perspect. 2016, 10, 39-49.

8. Gao, L.; Yan, J.; Du, Y. Identifying the turning point of the urban-rural relationship: Evidence from Macro data. China World Econ. 2018, 26, 106-126. [CrossRef]

9. Luo, Z.H.; Lin, L. Relationship between material consumption and income of Chinese residents and its spatial characteristics. Econ. Geogr. 2002, 2, 192-195.

10. Zhu, G.L.; Fan, J.Y.; Yan, Y. Sluggish consumption and income distribution in China: Theory and basis. Econ. Res. 2002, 5, 72-80.

11. Cao, G.Z.; Li, K.; Wang, R.M.; Liu, T. Consumption structure of migrant worker families in China. China World Econ. 2017, 25, 1-21. [CrossRef]

12. Guo, P.; Peng, N.Y. Study on the regional differentiation of China's residents' income increase to increase consumption efficiency. Financ. Theory Pract. 2012, 2, 80-84.

13. Fang, F.Q.; Zhang, Y.L. Analysis on marginal consumption tendency and changing trend of different incomes of urban and rural residents. Finance Trade Econ. 2011, 4, 22-30.

14. Lou, F.; Li, X.S. Dynamic empirical analysis on consumption demand of Chinese urban residents. Soc. Sci. China 2009, 3, 109-115.

15. Li, G.; Liang, J.Y. An empirical analysis of the impact of the three major income gaps on consumption. China Soft Sci. 2011, 3, 160-168.

16. Chu, D.Y.; Huang, W.Z.; Zhao, F. Regional differences, income inequality and consumption of urban and rural residents. Econ. Perspect. 2013, 1, 46-52.

17. Goh, C.C.; Luo, X.; Zhu, N. Income growth, inequality and poverty reduction: A case study of eight provinces in China. Soc. Sci. Electron. Publ. 2014, 3, 485-496. [CrossRef]

18. Tian, Q.; Ma, J.; Gao, T.M. Analysis on regional differences of influencing factors of urban residents' consumption in China. Manag. World. 2008, 7, 27-33.

19. Flavin, M.A. The adjustment of consumption to changing expectations about future income. J. Political Econ. 1981, 89, 974-1009. [CrossRef]

20. Modigliani, F.; Cao, S.L. The Chinese saving puzzle and the life-cycle hypothesis. J. Econ. Lit. 2004, 42, 145-170. [CrossRef] 
21. Chamon, M.D.; Prasad, E.S. Why are saving rates of urban households in China rising? Am. Econ. J. Macroecon. 2010, 2, 93-130. [CrossRef]

22. Sun, Y. The long-term and short-term relationship between consumption and income of urban residents with abrupt structural changes. Stat. Res. 2010, 3, 22-28.

23. Yan, Y.Y. Research Group, Comparative study on the dynamic relationship between consumption and income of urban and rural residents in China. Financ. Econ. 2012, 6, 49-51.

24. Wang, X.H. Changes in income structure, guidance of policies for supporting agriculture and extrication of rural consumption dilemma-A comparative study of temporal and spatial and regional differences. Financ. Theory Pract. 2013, 11, 1-7.

25. Yang, T.Y.; Liu, X.X. Research on the optimal income gap of residents satisfying the maximization of consumption. Economist 2008, 1, 77-85.

26. Lv, W.; Chu, D.Y. Research on income gap and economic growth of urban and rural residents. Econ. Perspect. 2011, 12, 30-36.

27. Xia, X.M. Analysis of regional differences in income and consumption level of urban and rural residents under dual economic structure. J. Northwest Univ. (Philos. Soc. Sci. Ed.) 2004, 5, 40-44.

28. Aziz, J.; Cui, L. Explaining China's low consumption: The neglected role of household income. Soc. Sci. Electron. Publ. 2007, 7, 1-36. [CrossRef]

29. Chen, B.K. Income distribution and consumption of Chinese residents-Theory and empirical research based on China. Nankai Econ. Stud. 2012, 1, 33-49.

30. Gao, F. Changes in China's urban-rural consumption gap: Analysis of characteristics, causes and turning points. Acad. Res. 2013, 10, 64-72.

31. Chu, D.Y.; Jing, T.R. Comparative analysis of the influencing factors upon urban and rural residents' consumption in our country. China Soft Sci. 2010, 4, 99-105.

32. Yang, T.Y.; Zhu, S.E. Research on the "inverted U" relationship between residents' income level and marginal propensity to consume in China. J. Renmin Univ. China 2007, 3, 49-56.

33. Kokoszka, P.; Reimherr, M. Introduction to Functional Data Analysis; Chapman and Hall/CRC Press: London, UK, 2017.

34. Ramsay, J.O.; Hooker, G.; Graves, S. Functional Data Analysis with R and MATLAB; Springer: New York, NY, USA, 2009.

35. Cuevas, A.; Febrero, M.; Fraiman, R. An anova test for functional data. Comput. Stat. Data Anal. 2004, 47, 111-122. [CrossRef]

36. Suhaila, J.; Jemain, A.A.; Hamdan, M.F. Comparing rainfall patterns between regions in Peninsular Malaysia via a functional data analysis technique. J. Hydrol. 2011, 411, 197-206. [CrossRef]

37. Leurgans, S.E.; Moyeed, R.A.; Silverman, B.W. Canonical correlation analysis when the data are curves. J. R. Stat. Soc. Ser. B 1993, 55, 725-740. [CrossRef]

38. Shin, H.; Lee, S. Canonical correlation analysis for irregularly and sparsely observed functional data. J. Multivar. Anal. 2015, 134, 1-18. [CrossRef]

39. He, G.; Müller, H.G.; Wang, J.L. Methods of canonical analysis for functional data. J. Stat. Plan. Inference 2004, 122, 141-159. [CrossRef]

40. Ramsay, J.O. Principal differential analysis: Data reduction by differential operators. J. R. Stat. Soc. Ser. B. 1996, 58, 495-508. [CrossRef]

41. Ramsay, J.O.; Silverman, B.W. Functional Data Analysis, 2nd ed.; Springer: New York, NY, USA, 2005.

42. Ramsay, J.O. Functional components of variation in handwriting. Publ. Am. Stat. Assoc. 2000, 95, 9-15. [CrossRef]

43. NBS (National Bureau of Statistics of China). China Statistical Yearbook; China Statistical Press: Beijing, China, 2017.

44. MOE of PRC (Ministry of Education of the People's Republic of China). The Notice about Cancellation of Compulsory Educational Children's School Tuition and Fees by State Council of the People's Republic of China. 2008. Available online: http://www.moe.gov.cn/jyb_xxgk/moe_1777/moe_1778/tnull_38125.html (accessed on 27 September 2018).

45. Xu, X.-J. Monetary expansion, investment constraints and household consumption: Theoretical model and China's experience. Econ. Rev. 2015, 3, 44-55.

46. Liu, G.C. Reasons for China's insufficient consumption: A summary. Mod. Econ. Sci. 2010, 6, 29-35. 
47. Wang, S.; Jank, W.; Shmueli, G. Modeling price dynamics in eBay auctions using differential equations. Publ. Am. Stat. Assoc. 2008, 103, 1100-1118. [CrossRef]

48. Yang, H.L.; Zhou, X.B. China's rural-urban and inter-provincial per capita income and consumption data highlight the phenomenological law. Econ. Res. 2012, s1, 38-52.

49. $\mathrm{Xu}, \mathrm{T}$. Income Diversification and rural consumption-Evidence from Chinese provincial panel data. Sustainability 2017, 9, 1014. [CrossRef]

50. Yu, L.R.; Luo, R.F.; Zhang, L.X. Decomposing income inequality and policy implications in rural China. China World Econ. 2010, 15, 44-58. [CrossRef]

51. Wu, X.M.; Wu, D. An empirical work on the relationship between the average propensity to consume and income distribution situation of urban households in China. J. Quant. Tech. Econ. 2007, 25, 22-32.

52. Liu, J.Q.; Sui, J.L.; Yan, C. A case study on the quantitative measurement of the convergence of China's interprovincial economic growth. Manag. World 2009, 10, 42-50.

53. Lin, Y.F.; Liu, M.X. Growth Convergence and Income Distribution in China. World Econ. 2003, 8, 3-14.

54. Zhou, G.A.; Xia, X. The Convergence and the Impact Factors of Regional Economic Growth in China. Stat. Res. 2008, 11, 3-8.

55. Wang, X.G. The Consumption Behavior Study of Urban and Rural Residents Using Structural Break. Stat. Inf. Forum 2013, 6, 38-44.

56. Gao, F. The inflection point of china's urban and rural consumption and its economic growth effect. Stat. Res. 2014, 12, 41-46.

57. Li, X.K.; Li, X.P. Influence of Income Inequality between Urban and Rural Residents on the Consumption Gap. Areal Res. Dev. 2016, 4, 12-21.

58. Guo, Q.W. Income strata hypothesis of consumption function. Econ. Theory Bus. Manag. 2013, 1, 5-9.

(C) 2018 by the authors. Licensee MDPI, Basel, Switzerland. This article is an open access article distributed under the terms and conditions of the Creative Commons Attribution (CC BY) license (http:/ / creativecommons.org/licenses/by/4.0/). 